\title{
Instructor Postings in Online Peer Discussion, Gender and Cognitive Style on Postgraduate Students' Participation, Social Presence, and Quality of Scientific Research Writing
}

\section{Dr. Mohammed A. Farag $\underline{\text { Abstract }}$}

This study was, a Web-enhanced course, designed to investigate the effect of presence and absence of instructor in an online discussion on learner participation, perceived social presence and quality of scientific paper writing. Gender and cognitive style were considered as moderating variables affecting participation, social presence and research writing skills. 52 postgraduate Master of Information and Communication Technology students, from the Faculty of Education-Albaha University in Saudi Arabia, participated in a Scientific Research Method course and were assigned to either a treatment condition (instructor intervention-instructor postings; $n=26$ ) or control condition (no instructor intervention-peer postings; $n=26$ ) for six weeks online discussions about designing experimental researches. Four discussion forums were designed as web-enhanced tools to accompany with a traditional research method course. Two forums were designed for male students and the other two were for females because mixed-sex discussions were not possible. Amount of participation was measured with the frequency and percentage of postings while the type of participation was analyzed based on a coding scheme rubric designed for this purpose. Learner's perceived social presence was estimated with a 30-item questionnaire type scale. Quality of learner in writing a scientific research paper was measure based on a 10 item-standardized rubric. Classifying participants into dependent and independent learners were done using the GEFT which was a post procedure. The results of the study revealed several significant differences. First, amount of participation in online discussion was affected by instructor intervention and gender type; with the peer facilitated condition produced more responses than instructor intervention condition and gender type was found to be a moderating effect with respect to amount of postings, with the male learners producing more postings. Cognitive style found to affect amount of postings with dependent learners being higher. Second, related and unrelated postings were affected by gender type, with the males posting more off-topic responses whereas for female the reverse was observed. Third, with respect to social presence, a significant effect was obtained with instructor interventions, with the peer facilitated treatment showing higher social presence than instructor presence treatment. Social presence was also found to be affected by gender type, with the females being feeling higher than males. Dependent learners had higher perceived social presence than independent learners. Fourth, quality of paper writing appeared to be affected by interventions and

\section{1}

\section{Journal of Arabic Studies in Education \& Psychology (ASEP)}


gender, with the no instructor condition increased writing quality and female participants being better. Finally, the study also found two and three way interactions. The results of the study were discussed in terms of their implications for designing online discussions.

Keywords: Instructor Presence, Online Discussion, Peer Discussion, Gender, Participation, Social Presence, Cognitive Style, Independent and Dependent learners

\section{INTRODUCTION}

Among all factors that could affect the level of learning in online environments, learner participation is recognized as one of the key elements and a serious success factor (Thompson \& Savenye, 2007; Weaver, 2008). Particularly, the constructivist paradigm called for learners to be active participants rather than passive receivers of information. Active learner participation is considered a must, especially in online learning environments where student perceptions about and needs for effective learning significantly differ from traditional face-to-face instruction (Dennen, 2005).

Participation in online learning environments is generally measured by the activities in discussion forums and message exchanges among learners and between the instructor and the learner. In line with the constructivist approach, online discussion forums depend on the idea that students are able to learn as much from one another as from course materials or instructors. In a discussion forum, a participant can have opportunities to express ideas, have them criticized, reshape ideas in light of peer discussions, and offer feedback on others' ideas. This exchange of ideas and works help students engage in higher-order processing of information and construct their own meaning.

The level of participation can be measured either by a qualitative or a quantitative approach. While the qualitative approach requires content analysis and classification of messages by certain criteria, the quantitative approach

\section{2}

Journal of Arabic Studies in Education \& Psychology (ASEP) 
focuses on countable merits such as the number of messages, the number of lines or words in a message, or time spent on discussion pages. In this study, participation is assessed by the number of messages in the discussion forum. Although a growing body of literature has been focused on discussion forums in online learning environments, the empirical relationship between student participation levels and performance is less than clear (Thompson \& Savenye, 2007). Scholars in the field also called for more studies on online learners and their needs (Gunawardena \& McIsaac, 2003; Richardson \& Newby, 2006).

Presence of instructor and characteristics of learners are significant factors for success in web-enhanced environments because they may shape the level of participation, which in turn affects the level of learning. Previous studies examined participation in relation to instructor presence and various student characteristics such as gender (e.g. Teo \& Lim, 2000); experience in online environments (e.g. Thompson \& Savenye, 2007), computer literacy (e.g. Erlich, Erlich-Philip, \& Gal-Ezer, 2005), motivation (e.g. Abel, 2005), and self-efficacy (e.g. Pituch \& Lee, 2006). Although it is widely accepted that performance is affected by student participation, variations in the level of performance for each student is moderated by instructor presence and individual differences. The present study was designed to reveal the effect of the instructor intervention in online discussion and two individual differences (gender and cognitive style) on learner participation, student's perceived social presence and performance in terms of writing a quality research paper.

With respect to the instructor presence in online discussion, studies have indicated a lack of consensus on the level of instructor intervention needed to effectively

\section{3}


facilitate participation and performance in asynchronous online discussions. Available data on the impact of instructor presence in asynchronous online discussion is inconsistent and can depend on whether the focus of discussion is to promote participation (Pena-Shaff, Altman, \& Stephenson, 2005) or learning (De Wever, Schellens, Valcke, \& Van Keer, 2006; Marra, Moore, \& Klimczak, 2004). One studies indicate that instructor presence and participation in asynchronous discussions enhance student learning (Beaudoin, 2002; Brookfield \& Preskill, 2012; Kearsley, 2000; MacKnight, 2000; Muirhead, 2005; Walker, 2005) and instructor presence may increase participation (Bedi, 2008; Beadouin, 2002; Mandernach, Dailey-Hebert, \& Donnelli-Sallee, 2007). Other studies indicate that instructor participation in online discussion can neutralize or hinder learner participation and learning (Andresen, 2009; Horton, 2000; Mazzolini \& Maddison, 2003; Swan \& Shih, 2005). Still other researchers argue that instructor involvement in online discussion can be beneficial to some degree when used in moderation (Guldberg \& Pilkington, 2007; Heckman \& Annabi, 2006). Regardless of findings, the common underlying assumption is that students have the potential to behave differently in online discussions based upon the presence or absence of instructor participation. With potentially conflicting research findings, instructors can become confused about how to support students in online discussions in webenhanced classrooms. Instructors want to support students and maximize both participation and learning, but previous research has primarily investigated the impact of instructor involvement on either student participation or on levels of learning. Results suggest that too little or too much intervention has the potential to prevent students from receiving the full benefits of the online discussion, but less is known about the impacts of instructor participation on the

\section{4}


combined student behaviors of participation, learner perception of social presence and performance.

Characteristics of learners are significant factors for success in online environment because they may shape the level of participation, which in turn affects the level of performance and social presence. Two of the individual differences that may have an impact on participation and social presence are gender type and cognitive style of learners. For gender type, previous studies in gender difference have showed mixed and inconsistent results with relation to participation. For example, studies on gender participation in computer mediated communication have found that males tend to post more and longer messages than females in mixed gender discussion (Jeong \& Davidson-Shivers, 2006).

Although females have been found to participate less than males, females have been found to be less disadvantaged in online discussions than in face-to face discussions (McConnell, 1997). In contrast, other studies found that females posted more messages than males (DavidsonShivers, Muilenburg, \& Tanner, 2000, 2001; Savicki, Kelly, \& Ammon, 2002) and females posted more substantive comments in both threaded discussions and chats in small groups. At the same time, studies have also found no significant differences between genders, and that the comments posted by males and females have been found to be similar in type and frequency in large group discussions and chats (Davidson-Shivers, Morris, \& Sriwongkol, 2003). These mixed findings could be attributed to differences in group-task (e.g., information sharing, argumentation, problem solving), task structure (e.g., graded participation, minimum required postings, assignment of roles or teams), and methods used to measure participation (e.g., message frequency vs. message-response frequencies).

\section{5}

Journal of Arabic Studies in Education \& Psychology (ASEP) 
Another important variable produced different result on participation is learner's cognitive style. Understanding student cognitive style may help instructors to understand student participation behaviors as well as social behaviors in a web-enhanced environment. Cognitive style was defined as the manner in which individuals organize and represent information during learning (Riding \& Cheema, 1991). According to Riding and Cheema (1991), cognitive style may be labeled into two main categories; the wholistanalytic dimension and the verbal-imagery dimension. The first dimension, considered in the present study, included the label dependent and independent cognitive style. Messick (1984) summarized the characteristics of analytical and global dimensions such that the field-independent pole includes competence in analytical functioning, combined with an impersonal orientation, while the field-dependent pole reflects correspondingly less competence in analytical function combined with greater social orientation and social skills.

The cognitive style factor is considered as a main variable affecting performance on tasks and how students tend to interact with different learning environments. Dependent learners may access the online part of the environment with the need of external help from instructor and peers, but independent learners are internally oriented and interact differently with the social environment (Moussa, 2005). The ways and manners in dealing with the social environment and the characteristic of dependent and independent learners should have an impact on how different cognitive style interact and participate in the learning environment. Studies directed to measure the impact of cognitive style on learner participation and social presence is rarely found in the literature, and so the present study should be a leading study in this direction.

\section{6}




\section{PROBLEM}

Scientific research methods course is considered as one of the important courses within the Master of Information and Communication Technology Program introduced by the Instructional Technology Department in the Faculty of Education-Albaha University. This course requires learners not only to achieving the lower levels of knowledge and skills, but also to apply these knowledge and skills in order to build an experimental research as a requirement for Master degree. Analysis of postgraduate complaints about the course showed that learners needed more discussion in the course in order to enhance their ability in writing a scientific paper. Discussion in traditional classroom is not enough to provide learners with the knowledge and skills required to submit a quality paper. Another important issue related to this problem was the concern raised by participants in the course related to their perception of being a part of a community and their feeling of social connectedness with other learners. Most students were not satisfied with the scientific research methods course, which might have affected their ability in writing a scientific paper. Based on the analysis, the researcher found that the minimum basic knowledge and skills required for the course were not met and learners' needs for more discussion and participation were a mandatory requirement. Therefore, the researcher defined the problem and instructional needs based on students' current level of knowledge and skills in the course and the requirements raised by students to having more discussion about and participation in the course topics. As for the required level, the analysis showed that students should have the basic skills and knowledge of the steps and stages of building a quality paper and these skills and knowledge could be gained by increasing students' discussion and social connection with the instructor and peers. As a result of this analysis, the researcher suggested

\section{7}


that creating an asynchronous online discussion as a webenhanced tool complemented the traditional classroom course would assist in increasing participation and performance. In order to put the problem one step further, a revision of studies interested in online discussion was done to figure out the best approach to increase student participation and performance. One of such approaches was to have the instructor involved or not in the online discussion. Another approach to increase participation for both males and females particularity in Saudi Arabia, a society with a single-gender discussion is to have a single gender discussion. Mixed gender participation is quite difficult to have in this society. Therefore, taking a gender type as a moderate factor in studying participation was also important. Finally, cognitive style of learners was also considered.

\section{THE STUDY PURPOSES}

The overall purpose of the present study was to investigate the moderating effects of instructor intervention in online discussion and individual differences on postgraduate learner's participation, perceived social presence and quality of scientific research writing in a webenhanced course. More specifically, the study was designed to reveal the effects of the instructor presence in online discussion and two individual differences have on types and amount of student's participation, social presence of learners, and scientific research writing skills. In supporting this purpose, the primary objectives are twofold. The first objective was to investigate the effect of instructor postings on postgraduate learner types and number of postings, their perceived social presence and their ability in writing an experimental research paper. The second objective was to uncover whether or not a learner cognitive style and gender type would change learner's types and amount of

\section{8}


participation, their perceived social presence and quality of writing a research paper.

\section{QUESTIONS}

The present study addressed the following four questions:

- What is the effect of the instructor presence in online discussion on participation, learner's perceived social presence and quality of scientific research writing?

- What is the effect of gender type on participation in online discussion, learner's perceived social presence and quality of scientific research writing?

- What is the effect of the independent-dependent levels of cognitive style on participation in online discussion, learner's perceived social presence and quality of scientific research writing?

- What are the interactions (if exist) among instructor presence, gender and cognitive style on participation, social presence and quality of scientific research writing?

\section{SIGNIFICANCE OF THE STUDY}

This study should contribute theoretically and practically to the on-going technology-enhanced learning research and modern teaching methods studies. The importance of the present study is as follows:

Since online discussions have become common in all online course, blended course or in the present study as a web-based tool to enhance traditional learning, further examination of the features and design elements of online discussions may assist in increasing effectiveness of this tool.

Research in online discussions suggests numerous interventions to address learner participation challenges identifiedin the literature. These interventions underestimate the important role of the instructor in designing, facilitating, and supporting asynchronous instruction (Abawajy, 2012; Andresen, 2009; Guldberg \& Pilkington, 2007; Swan \&

\section{9}

Journal of Arabic Studies in Education \& Psychology (ASEP) 
Shih, 2005; Thompson, 2010). Most suggest that the instructor has the ability to either increase or decrease student quality and quantity of participation, which demonstrates the importance of further investigation into the effect of the instructor feedback in online discussion on participation and quality of student learning. While further research is needed to explore specific strategies students employ when posting with and without instructor intervention, the findings of this investigation add to existing research-based findings and offer insights relative to the use of instructor interventions in asynchronous discussions.

This study sought to fill a gap in the instructional technology literature about the effect of structuring online discussion based on instructor interventions and the other individual differences on participation, social presence and quality of student scientific paper writing. There is a shortage in research investigating gender and cognitive style of learners as possible factors affecting participation. Further, social presence research is rarely considered leaner cognitive style and gender with respect to social presence. Information about these variables should encourage more interest and provide practical guidelines to reshape student quality of engagement in online discussion. A great deal of research has been done on online discussions. Previous research has mainly focused on two topics: participation and online collaboration. A few researchers have studied gender type and cognitive style and participation, with relation to instructor presence or absence. This study is a trial in this respect.

The significance of this study relates to creating a better understanding of factors influencing participation, social presence and student's ability in writing experimental research. By examining the instructor interventions, gender

\section{0}


type, and cognitive style, instructors and instructional designers may be able to modify the design of online discussions so as to increase participation levels by learners. By increasing levels of participation, the instructors and designers may indirectly have a contribution to increase Student's perceived social presence and performance.

\section{HYPOTHESES}

This study had one independent variable (instructor interventions), two classified variables (learner's cognitive style and gender type) and three dependent variables (participation, social presence and quality of research writing). The hypotheses of the study may be written as follows:

Null Hypothesis One: With respect to the instructor interventions, there would be no significant difference at $\alpha=$ .05 level in amount and types of student participation as measured by the mean number of postings and participation rubric between the instructor intervention online discussion group and no instructor intervention online discussion group.

Null Hypothesis Two: With respect to the gender type, there would be no significant difference at $\alpha=.05$ level in amount and types of student participation as measured by the mean number of postings and the participation rubric between male and female participants.

Null Hypothesis Three: With respect to the cognitive style, there would be no significant difference at $\alpha=.05$ level in amount and types of student participation as measured by the mean number of postings and the participation rubric between independent and dependent participants.

Null Hypothesis Four: With respect to the instructor interventions, there would be no significant difference at $\alpha=$

\section{1}


.05 level in learner's perceived social presence as measured by social presence scale between the instructor intervention online discussion group and no instructor intervention online discussion group.

Null Hypothesis Five: With respect to the gender type, there would be no significant difference at $\alpha=.05$ level in learner's perceived social presence as measured by social presence scale between male and female participants.

Null Hypothesis six: With respect to the cognitive style, there would be no significant difference at $\alpha=.05$ level in learner's perceived social presence as measured by social presence scale between independent and dependent participants.

Null Hypothesis Seven: With respect to the instructor interventions, there would be no significant difference at $\alpha=$ .05 level in quality of writing scientific research as measured by learner scientific research paper rubric between the instructor intervention online discussion group and no instructor intervention online discussion group.

Null Hypothesis Eight: With respect to the gender type, there would be no significant difference at $\alpha=.05$ level in quality of writing scientific research as measured by learner scientific research paper rubric between male and female participants.

Null Hypothesis Nine: With respect to the cognitive style, there would be no significant difference at $\alpha=.05$ level in quality of writing scientific research as measured by learner scientific research paper rubric between independent and dependent participants.

Null Hypothesis Nine: In terms of participation, social presence and quality of scientific research writing, there

\section{2}


would be no interactions of instructor presence, gender and cognitive style.

\section{THE STUDY METHOD}

This study belongs to the type of experimental research, which aims to study the causal effects of selected variables, and the experimental method is the most appropriate research methods to achieve this purpose. Therefore, the present study follows a quasi-experimental design to study the effects of one independent variable and two classified variables on three dependent variables.

\section{PARTICIPANTS}

The participants of this study $(\mathrm{N}=52)$ were postgraduate students, at Albaha University in Saudi Arabia, who were studying Scientific Research Method Course in Master of Information and Communication Technology in Education. The Master Program required students to complete four study levels before submitting their thesis research. This course of study is a traditional course students have in the second level of study period. The participants of the study were males and females (males $\mathrm{N}=27$ and females $\mathrm{N}=25$ ). The participants' age was ranged from 25-48 (males $\mathrm{M}=32.87$ and females $M=27.62$ ). Students in the course had different major backgrounds such as computer major, Arabic language major, science major, Islamic studies major and so on, but a Diploma in Education or A Learning Resource Center Diploma was required to join the Master. All students had the necessary skills and experience to deal with the online discussions. Because studying in Saudi Arabia required a separation between males and females, so the discussion forums created were single-sex discussions, a mixed gender was not possible to create.

\section{THE STUDY VARIABLES}

This study included one independent variable, two classified variables and three dependent variables. The independent variable was instructor intervention, which had

\section{3}


two levels-instructor interventions in the online discussion versus no instructor interventions. The classified variables were gender type and cognitive style. Gender was classified into females and males, whereas cognitive style was classified as dependent and independent learners. The dependent variables were learner participation, learner's perceived social presence and learner's quality of writing scientific research.

\section{The Independent Variables}

This study had one independent variable, instructor intervention in online discussions, with two levels of this variable: (a) instructor intervention and (b) no instructor intervention. Instructor intervention: is a treatment where the students in the online discussion received instructor postings during the discussion. The no instructor intervention: is a treatment where the students in the online discussion received no postings from the instructor, but students depended on their peers' feedback. The present study had two classified variable, and these were; a) gender type, and this variable classified participants into males and females; and b) cognitive style, and this variable classified participants into field dependent (FD) and independent (VI ) learners. Participants were divided into FD and VI based on the GEFT measurement.

\section{The Dependent Variables}

This study included three dependent variables: learner participation, learner's perceived social presence, and quality of writing.

Learner participation: this variable was based on the written messages learners posted to online discussion and was measured in two ways: (a) amount of participation was calculated by the number of student responses, and (b) type of participation was measured using a modified coding scheme adapted from Davidson-Shivers et al. (2005) and

\section{4}




\section{Number 74, June, 2016}

Jeong and Davidson-Shivers (2006). The modified coding scheme used by Farag (2016, In Press) was used in the present study. Reponses were grouped into on-topic and offtopic depending on relatedness with the question posted in the discussion forum and content of discussions.

Learner's perceived social presence: this variable was measured using a 30-item Likert scale questionnaire. Social presence was a scale divided into four sections, with fiveresponses ranging from strongly agrees to strongly disagree. More about building this scale is detailed later.

Learner's quality of scientific research paper writing: this variable was measured through a rubric of ten standards and 70 -item indicators.

\section{EXPERIMENTAL DESIGN}

The quasi-experimental design was used to study the effects in the light of the independent variable level, and this is represented in table below. The learners in the present study were blocked by instructor intervention and gender type into four discussion forums as follows.

Table 1: The study experimental design

\begin{tabular}{|c|c|c|c|c|}
\hline & & \multicolumn{2}{|c|}{$\begin{array}{c}\text { Instructor intervention (presence of } \\
\text { Instructor) }\end{array}$} \\
\hline & & Instructor Postings & No Instructor Postings & Total \\
\hline \multirow{2}{*}{$\begin{array}{c}\text { Gender } \\
\text { Type }\end{array}$} & Male & 14 & 13 & 27 \\
\cline { 2 - 4 } & Female & 12 & 13 & 25 \\
\cline { 2 - 4 } & Total & 26 & 26 & 52 \\
\hline
\end{tabular}

Fifty two students participated in the present study. Of 52,26 learners were assigned to the instructor postings group (male $\mathrm{N}=14$ and female $\mathrm{N}=12$ ) and the other 26 assigned to the no instructor postings group (male $\mathrm{N}=13$ and female $\mathrm{N}=13$ ).

\section{THE STATISTICAL ANALYSIS}

The multivariate analysis of variance (MANOVA) as a main tool was used in order to study the effects and

\section{5}


interaction of the independent and dependent variables of the study.

\section{THE STUDY TOOLS}

\section{Cognitive Style Measure:}

In order to classify the participants of the present study based on their cognitive style tendency, the GEFT (Group Embedded Figure Test) was used to classify the participants into field dependent (FD) and field independent (FI). This measure was originally developed by Oltman, Raskin, and Witkin (1971). The Arabic Version of the Test (Appendix A), developed by Alsharkawy and Al-Khoudary (2002), was used. The GEFT in its original form is an untimed paper and pensile test including 18 items but the Arabic version is timed. There are also seven items for practice. Each item in the test represents a simple geometric figure embedded in a complex design. The GEFT scale has three parts; part one is a training section; it starts with some instructions on how to respond to the figures provided and gives some examples of responses. Then, seven shapes are introduced and subjects are allowed two minutes to give response but scores for this response are not calculated. Part two and three, each part has nine shapes and gives each participant five minute to respond; with the 10 minutes for parts two and three are given. The total score on the measurement is calculated based on student response on the 18 shapes included in sections two and three of the scale. For each item, the participants should locate and trace the simple shape containing in the complex drawings without becoming distracted by the larger complex design. The total score is the number of items correctly perceived and traced. Thus, the scores range from zero (highly dependent) to 18 (highly independent). Higher scores represent a more field independent (FI) cognitive style while lower scores show more field dependent (FD) cognitive style. The reliability of the Arabic version of the GEFT for the current study was

\section{6}


examined by correlating learners' performance in the two halves of the test (items 1-9 the first half, and items 10-18 the second half). To estimate the reliability of the whole test (internal consistency), Spearman-Brown formula was used. The reliability coefficient for the total test was 0.86 .

\section{Participation Measures}

Participation in online discussion was evaluated using two measurements; one was the numeric count of student responses, the other was deep analysis of responses using student's responses rubric. The first measure was used to measure number of message students posted in the online discussion. The four discussion forums designed as tools to enhance the traditional classroom method were printed on sheets of paper to see the number of responses each student posted and inserted in the SPSS software for processing. The second measure was a student response rubric, developed by Farag (2016, In Press). The coding scheme splits student's responses into substantive and nonsubstantive responses based on to what extent the response was related to the question and topic of discussion (Appendix B). Substantive related on topic responses codes were applied to students' responses that were related directly to the discussion content and topic. Non-substantive unrelated off topic responses were not relevant to the discussion topic or content. The original coding scheme used with the present study was developed by DavidsonShivers et al. (2005) and from Jeong and Davidson-Shivers (2006). The authors, originally, divided substantive related codes into response, evidence, criticism/critique, elaborate, and evaluation; but for non- substantive responses, three codes were created and these were technical, chatting, and uncodable. The present study used the modified coding scheme developed by Farag (2016, In Press), who, added two other codes to the original coding scheme; one was substantive (restate); one was non-substantive (sidetracked/

\section{7}


deviation). Restate was a response given by student which restates the peer's idea but does not extend the original idea or adding any significant contribution to the discussion. Therefore, restate responses were defined as restating another's idea but not extending the idea. Sidetrack responses were defined as making a comment that was related to the communication or the topic of discussion but was not directly related to the original discussion question. Overall, the present study was mainly dependent on Farag (2016, In Press) coding scheme.

\section{Social Presence Questionnaire}

In order to establish a measure of learner's perceived social presence, several studies and researches have been reviewed to reveal the underlying components of this terminology. The results of the review showed that social presence has been documented and researched but unfortunately this construct was defined in many different ways, but there were semi-agreement on four basic components, and these included: interest and mutual support the learner gains during interacting with the online environment, the emotional connections among learners within the environment or the affective connectedness, feelings or sense of belonging to a community during interaction, and finally the open communication among learners in the environment. Based on these four components, the researcher established a four-component scale to measure student's perceived social presence, and these components were:

- Mutual attention and support the learners had within the online discussion

- Affective connectedness in the online discussion

- Sense of community in the online discussion

- Open communication in the online discussion

The survey instrument developed by the researcher was administrated at the conclusion of this study to estimate how 
high or low students' feeling of social presence within the online discussion (Appendix C). The first part of the survey was a section requiring subjects to provide some personal information such as gender, age, teaching experience, computer experience, and online discussion experience. The second part of the survey provided students with some instructions on how to response to the survey statements. The instructions were: below you will see a series of statements (30 items) concerning how you felt about online discussion you have just joined during studying Scientific Research Method Course. Read each statement carefully and place a tick $(\sqrt{ })$ in opposite to the left of the statement that comes closest to indicate how you feel about the online discussion. There are no correct or incorrect responses. Do not spend too much time on any one statement, but give the response that seems to describe how you feel, Please respond to all statements. Use the five scale measure to select your response from five ones.

After these instructions, thirty statements were provided with a Likert-scale type of five possible responses, ranging from strongly agree to strongly disagree. Section one of the statements included twelve (12) statements, section two included six (6) statements, section three consisted of eight (8) statements, and finally the last section included four (4) statements. High responses on the survey items reflected positive social presence for all but four items. The scale for these four items (item seven, eight, twenty four and twenty six) were reversed to maintain consistency in the scales. Cronbach's alpha scores range from (0) through (1), with a coefficient closer to (1) indicating higher reliability. Reliability coefficients should be at least 0.70 or higher to be considered reliable for affective instruments. The Cronbach's Alpha for the questionnaire items was 0.81, which indicates a high degree of internal constancy in a

\section{9}


multi-item scale. The $95 \%$ confidence interval for the mean of the questionnaire was 3.551 to 3.932 .

\section{Scientific Research Paper Rubric}

The main objective of building a rubric for scientific paper writing was to create and develop a set of common standards and indicators that would help, assist and enable evaluators of the research paper to use a fixed unified scale to assess learner's scientific paper writing. Leaving evaluators to use their views and opinions while assessing the quality of paper is not seen as a good measure since evaluation would not be fair because of lack of objectivity, therefore establishing a rubric for evaluation would be a better solution. The main objective of the rubric used in the present study was to evaluate how satisfactory would be the paper provided by Mater of Information and Communication Technology in Education Students in the Scientific Research Method course. The course required subjects to submit an experimental research paper majoring in instructional technology. In traditional methods of evaluating students' research papers, a panel of five to seven professors specialized in instructional technology in the department of instructional technology in the Faculty of education-Albah University are required to provide their views and opinions for decision to be made. This manner of evaluation is a good one, but providing the panel of specialists with a rubric for evaluation would help and assist them with a better evaluation. In the present study, the rubric was given to a panel of three evaluators for assessing students' papers.

After reviewing several researches and studies, the research reached a conclusion that a scientific research paper had to include seven main standards such as: title, abstract, introduction, method and material, results, discussion, and literature review. When designing the rubric

\section{0}


used in the present study, the researcher used this framework to build a set of standards and indicators for evaluating the research paper, and this rubric included, in its final form, ten standards with 70 indicators. For example, Title standards consisted of 12 indicators that described how to write a good title that is brief, informs of the topic, and shows the subject scope and the variables. Title should also be clear and written in a simple language with good organization and rules. The distribution of the indicators with each standard in the rubric as follows:

- Title: (12) indicators

- Abstract: (10) indicators

- Introduction: (10) indicators

- Method: (9) indicators

- Results: (10) indicators

- Discussion: (8) indicators

- Conclusion or Summary: (3) indicators

- References: (6) indicators

- Grammar and Spelling: (1) indicator

- Paper organization: (1) indicator

For scoring students' papers, each standard with the accompanied indicators had a point on the rubric. For example, title of the paper was allocated twelve points while introduction, method, and discussion sections were given eighteen points each. The results and abstract standards were given nine points for each while the conclusion and reference standards were allocated five points each. Finally, the grammar or spelling and the organization of the paper were given three points for each. The total score student had with the research paper was the number of points given by the evaluators with each standard, then the sum of all points in the ten standards was the final grade on the paper writing. Three raters evaluated the student's paper, then, the mean raters were calculated for analyzing the data. The total score

\section{1}


on the rubric was 100 points. On the top of the rubric, evaluators were given with instructions and these were: "Dear evaluators, the rubric between your hands was designed to measure student's ability to write a good research paper and how quality the paper was written based on the ten standards provided below". Following these instructions, the standards were provided and the manners on how the evaluators would follow to evaluate the paper were given as follow: "Dear evaluators, in order to facilitate your evaluation of the student's paper, the criteria used for evaluation are divided into ten standards with a range of indicators under each criteria or standard with the accompanied scores. At the end of assessing each standard, a total score can be summed for all standards which indicate the total paper evaluation. Dear evaluators, please notice that the scale is a four-point measure, which shows how good the paper is based on availability of the standards and indicators in it, therefore your evaluation should follow this four-item scale".

In order to measure validity and reliability of the measure, the researcher followed some rules. A content validity was estimated to ensure that the measure fits specifications for the domain of behaviors it is intended to cover. The measure was submitted to a panel of 10 specialists in instructional technology, instructional psychology and teaching method fields for judgment of course contents and its objectives. The rubric was then revised on the bases of this judgment, and amendments were conducted in terms of adding, deleting and rephrasing the indicators and items. Percentage of raters' agreement was $88 \%$. Rubric Reliability ranged from 78 to 91 for standards, and total reliability of the scale was 83.7.

\section{DESIGN AND PROCEDURES}

Context: in this study, the Facebook group was used in one web-enhanced course at the Faculty of Education -

\section{2}




\section{Number 74, June, 2016}

Albaha University in Saudi Arabia. The course was offered for Postgraduate Mater students in Information and Communication Technology in Education. 52 participants took the course in the second semester of 2014, and their ages varied from 25 to 48 . There were 14 traditional face to face classrooms with 6 weeks online discussions. The course titled as Scientific Research Methods, and was similar for both male and female participants in its traditional and electronic parts.

The main tool in the present study was an online discussion which was used as a web-enhanced tool to assist learners engaging in deep interaction about the content topics. Four discussion forums were created using the features of Facebook. Two forums were used for male students and two for females. One forum was established to facilitate peer discussion without intervention from the instructor, and the other, interaction among learners was intervened by the instructor postings. This was done for males and females.

Setting Up a Facebook Group: the instructor created a Facebook group before the course starts. The access mode of Facebook was first set to "Open to public" so that access did not require participants to be friends. After all students joined the Facebook groups, it was closed so that it could be kept away from random access of other visitors. The activities carried out in the Facebook group included putting up announcements, sharing course resources and conducting online discussion.

Facebook was chosen as a platform for discussion for several reasons. Facebook provides instructors opportunities and structures by which students can help and support one another and it also increases both teacher-student and student-student interaction. Apparently much similar to applications available in any typical learning management systems (LMS), Facebook may be used by course facilitators in a variety of ways to help engage students in

\section{3}


the learning process. Some of these include uploading course announcements, announcing events, posting reminders regarding assignments, creating links to educational resources such as video clips and relevant websites as well as facilitating discussions either on the wall or in discussion boards. Such activities help foster conversation and enhance learning in a community of learners. The beauty of this is that students themselves have the same opportunity to take on responsibility and ownership in building their community of learning. They may themselves post announcements and reminders for fellow students, ask questions of their facilitator or peers or help answer other students' queries. Another important features for using Facebook as a platform for discussion is that The ability to integrate Facebook into smartphones and tablets makes the platform more immediately accessible than traditional LMS discussions, where a student will often have to navigate a number of screens to $\log$ in to a university system, then the LMS, before being able to access a discussion board. This is potentially useful for both students and staff who are able to be promptly made aware of activity in an online discussion and have the option of responding quickly.

Putting Up Announcements: the wall in the Facebook group was used to spread just in time information. The wall allowed the publication of announcements, which included hyperlinks, picture and videos. The wall allowed participants to share resources and get feedback from others. Another helpful feature of the wall was that whenever a discussion topic or a picture was created in the Facebook group, it would automatically appear on the wall, which makes keeping track of the activities happened in the group convenient.

Sharing Course Resources: course materials may exist in any format such as a test file, PPT presentation, or a Pdf document. But Facebook could only work with materials in 
either a picture or a video format. A third party application -Google Docs was used to negate the short fall of Facebook. A file in a different format was first uploaded to Google Docs. The address generated from Google Docs was then copied on the Facebook group. Clicking on the address link would open the file. To further facilitate the ease of access, Google Docs was configured in such a way that the students needed. No Google account to access the file was needed.

Conducting the Online Discussion: two different ways of conducting online discussion were explored. One way was to use the feedback space located under the event function, and the other way was to use the default discussion function located on the Facebook group. It was found that using either way for discussion could help sharing ideas but both had limitations. Facebook simply added a response to the end of the discussion without taking into account if the response was referring to a particular post. Students had to deliberately repeat the previous postings in their present comments in order to make the comment between the two postings clearer.

Setting Up Expectations for Participants: participants were given minimum participation expectations at the beginning of the semester. These expectations set forth the minimum number of original posts as well as response posts that each participant should produce. Participants were encouraged to engage in the online discussions beyond these minimal expectations. Participants were requested to post a minimum of three original posts and gave a comment of their peer posting for each question posted by the instructor. The instructor posted one question for discussion each week for a six week period. The question was an open question which required a debate among participants. Comments and postings from participants were recorded

\section{5}

Journal of Arabic Studies in Education \& Psychology (ASEP) 
and coded according to a participation rubric. Students also were requested to focus their comments and posting on the topic of the questions, and they also had the choice to elaborate, evaluated, restate, and critic the other comments. The researcher coded each complete statement in its entirety. If different parts of one statement could be coded at different levels, the researcher assigned the entire statement the highest category that was evidenced. Four discussion groups had the same instructions for participation with a single gender interaction, but the intervention of the instructor was differed. Two groups (instructor intervention groups), one for males and the other for females received at least 6 to 8 postings from the instructor each week; while for the other two groups (no instructor intervention) received no postings from the instructor. This arrangement was continued for six weeks. The no instructor groups had no instructor interventions for the whole six weeks whereas the instructor intervention groups received minimum 6 or 8 postings each week for six week period. Moreover, participants were told that their participation in the discussion forum and their contribution were graded and given points and scores and affected their performance on the course.

After participation for six weeks, all postings from the groups were recorded and analyzed based on the participation rubric designed for this purpose. Immediately on finishing the discussion, students were given a social presence scale, an Arabic version of the GEFT. Finally, participants were given three week period to end with their paper writing.

\section{DEFINITION OF TERMS}

- Online Discussion: it is a chain of written ideas or opinions exchanged among two or more participant, and linked in a sequence in which they espoused by the

\section{6}




\section{Number 74, June, 2016}

participants. It enables the instructor to post a question or prompt and students respond. It also enables students to respond to each other. Online discussions, is also defined here, as forums, which represents a type of electronic communication among group of individuals in which one person can post a question or comment, others can read it and reply, and then still others can read and comment on those replies.

- Social Interaction: In this study, social interaction is defined as any purposeful communication that occurs between two or more individuals in a learning environment.

- Social Presence: Social presence involves both the ability to affectively and socially perceive the presence of others and the ability to affectively and socially project oneself in online discussions. It is not a concept merely showing recognizing others' being but rather, it goes beyond that to reflect the dynamic of the social relations with others. Therefore, the concept included four important factors which are mutual attention and support, affective connectedness, sense of community, and open communication.

- Quality of Participation: it is defined as the type of response that students provide. There are two levels of student participation, on-topic and off-topic, which related to how connected student responses were to the discussion content. On-topic participation is related directly to discussion content; off-topic participation is not (Farag, 2016, In Press).

- Quantity of Participation: it is defined as the number of messages that students posted to discussions.

- Instructor interventions: it is defined as the messages students received from the instructor during discussion. It is also defined as the presence of the instructor in the

\section{7}


online discussion by providing students with posts in the forms of feedback (questions, comments ...etc.).

- Cognitive style: Cognitive style refers to the preferred way that an individual processes information. Cognitive style describes an individual's typical mode of thinking, remembering or problem solving, and it is usually considered to be bipolar dimensions and stable over time. Cognitive style refers to an individual's habitual manner of processing and representing information (Riding \& Cheema, 1991). In this study, cognitive style refers to students' cognitive style of field dependency.

- Field-Dependent Cognitive Style: Field-dependent individuals are more focused on the whole rather than the part. They tend to approach a problem in a more global way, are socially oriented, prefer collaboration, and are extrinsically motivated. In this study, fielddependent cognitive style is measured by the Arabic version of Group Embedded Figured Test (GEFT)..

- Field-Independent Cognitive Style: Field-independence refers to individuals whose perception is independent of the surrounding visual framework. They tend to focus on parts rather than on the whole. They tend to approach a problem more analytically, prefer competition, and are intrinsically motivated. In this study, field-independent cognitive style is also measured by the Arabic version of GEFT.

\section{THEORETICAL FRAMEWORK}

The purpose of this study was to investigate how a particular online instructor affects learner participation and learner social presence in asynchronous online discussion, and how the gender type affects participation. The study also was interested in investigating the effect of cognitive style on learner participation and leaner perceived social presence. Besides participation and social presence, the present study was interested in revealing the effects of the

\section{8}




\section{Number 74, June, 2016}

three independent variables (instructor presence, gender and cognitive style) on performance as measured by a quality of research paper writing.

\section{Online Discussion and Facilitation}

\section{Attributes of Online Discussions}

Webb, Jones, Barker, and Van (2004) defined online discussions as interactions between students and teachers as well as exchanges among students and others in the form of reflective thought. Online interactions facilitate social and collaborative learning processes and support the shift away from a teacher-centered traditional approach toward a student-centered approach, involving a constructivist teaching paradigm (Stacy \& Rice, 2002). Importantly, interaction between learners and learners, and learners and instructor, is the focus of online learning. Participation in discussions and awareness of deadlines are imperative to engaging students in online discussions because by doing so, the course becomes more learner-centered allowing for decentralization of the learning process (Gulati, 2008).

Online learning can be exciting, interactive, purposeful, and beneficial if the instructor fully maximizes the effectiveness of online instruction by creating active learning experiences to enhance the meaningfulness of content knowledge. Facilitation by instructors may be done by questions that specifically elicit on-topic discussions, guidelines to help online learners prepare on-topic responses, rewording of the original questions when responses were going in the wrong direction, and providing discussion summaries on a regular basis were the key factors supporting successful online discussions.

\section{Online Discussion}

The asynchronous online discussion approach is an appropriate pedagogical tool that enhances learning opportunities (Bali \& Ramadan, 2007). Through

\section{9}


asynchronous online discussions, students can participate in class discussions online outside of class without time and distance boundaries. According to Canter et al. (2007), asynchronous discussions provide learning opportunities through an electronic board, which allows texts and documents to be uploaded. Learning through asynchronous online discussions occurs in delayed time and does not require the simultaneous participation of discussants (Thurlow, Lengel, \&Tomic, 2004). In addition, Bali and Ramadan (2007) noted that the online format provides the opportunity and encouragement for students who are shy to speak up in class so that they are more comfortable participating in online discussions.

From a constructivist perspective, online asynchronous discussions help create learning opportunities for students. According to Wozniak (2007), learners in asynchronous discussions have more flexibility and are able to control when they are ready to post and respond to others' messages in a discussion forum. Asynchronous discussions are normally used to (a) keep in regular contact with students while off campus, (b) encourage students to review learning material, (c) assist student to learn from each other, and (d) encourage self-reflection, critical thinking, and selfevaluation.

To promote social interaction between learners, the instructor needs to create a real learning environment in which discussion board forums can also be used to stimulate conversations regarding a specific topic. Participation by the instructor in discussions and effective planning are required to engage students in online discussions (Cheung \& Hew, 2010). Doing so, students' critical thinking and reflections on their ideas will be improved. Based on constructivist theory, asynchronous discussion, a student-centered teaching method that uses online learning resources to

\section{0}


facilitate information sharing outside the constraints of time and place among a network of people is applied (Johnson \& Buck, 2007). Importantly, students will have more opportunities to construct meanings together, integrate new knowledge into their prior experiences, and apply their knowledge and understanding to their real life (Correia \& Baran, 2010). In addition, the goals of asynchronous discussions are to share ideas and opinions, promote learner-to-learner participation, and encourage formation of collaborative online groups.

In conclusion, students and instructors in asynchronous online discussions are allowed to interact in social environments without the boundaries of time and distance (Johnson \& Buck, 2007). The integral factors to develop and manage an asynchronous online discussion forum in the appropriate manners are to create an effective online learning environment that leads learners to achieve higher levels of learning. Asynchronous online discussions definitely help reduce face-to-face classes; therefore, students with distance issues have more opportunities to participate in classes. Given the focus of this study, and the importance of organized instruction in asynchronous learning environments, research relating to the role of the instructor must be explored. Before explaining the issue of the effect of the instructor presence in online discussion, challenges with online discussions are presented.

\section{Challenges in Online Discussion}

Researchers have identified numerous challenges associated with the use of asynchronous discussions for learning purposes. A crucial problem is lack of student participation (Andresen, 2009; Brookfield \& Preskill, 2012; Conrad \& Donaldson, 2011; Hammond, 2005). Not all students relish the opportunity to make their views known or to engage in scholarly discourse. Letting learners know

\section{1}




\section{Number 74, June, 2016}

how important these discussions are to learning may help but will not necessarily guarantee participation. To better understand how to support students in asynchronous discussions, instructors may wish to consider reasons behind student reticence. Coomey and Stephenson (2002) point out that - Instructors and course designers cannot assume that learners will be able to jump into group discussions, argue in online debates, or answer questions posed online, just because they are told to participate $\|$ ( $\mathrm{p}$. 39).

Another potential reason for student limited contribution in online discussion is the lack of familiarity with the technology. For example, in a study of 20 graduate students, Murphy and Coleman (2004) found that design elements such as the inability to flip back and read through discussion postings while composing a message, and the way the discussion software system constantly returns students to the top of the listings when they click to expand a thread resulting in students having to search through the entire postings to locate where they are frustrate students who want to contribute their ideas. Another technical aspect that limits the contribution of students is the inability to edit and delete messages (Murphy and Coleman 2004). Such an inability made some students feel like a fool throughout the entire course because they were unable to change a posting mistake. Furthermore, it caused students a lot of time and effort to rectify an error in a message-for example, students had to explain what they said that was wrong, said what they actually meant to say, explained their arguments again, made the correction before someone else responded to it and confused the issue even more. Thompson (2013) suggests that $t$ enhance students with the target technology, students should have training or should have scaffolding at the beginning of a course to ensure familiarity with the

\section{2}


specific technology. The same notion was asserted also by Ko, Ko, and Rossen (2010) and Pattoff and Pratt (2010).

In addition to lack of familiarity with new technology, learners may also experience discomfort when responding within the context of unknown group. This concern may or may not be applicable to the present course since students know each other in the traditional part of the course (the present course is a web-enhanced), depending on whether students are presented opportunities to form relationships FTF prior to the online discussions. Researchers suggest that students must develop relationships first, prior to engaging in serious scholarly discourse (Dennen, 2005; Guldberg \& Pilkington, 2007). In line with argument, Previous research has also suggested that the behavior of other participants (e.g., other students, instructors) can limit student contribution in asynchronous online discussion (Hew and Cheung 2003a, b). Students cease contributing if they receive no immediate response or comments to their questions from other students. For example, Cheung and Hew (2004) found that some students procrastinated in responding to other people's questions, resulting in great frustrations for those students who were waiting for answers. The delay caused the students to feel that they were speaking into a vacuum; that no one was responding to them, so why bother writing messages. Studies also suggest that students stop contributing if they perceive that other students pontificate in the online discussion (e.g., giving their opinions about something as though they know everything about it), or if they feel threatened by other students or if the tone of the discussion becomes too emotional (Hewitt, 2005), or rude (Murphy \& Coleman 2004).

One important factor that ceases student participation is the perception of importance of the topic of discussion.

\section{3}


Zhao and McDougall (2005) found that low student participation may result from students' feelings that the discussion topics not interesting and therefore not worthy of discussion. In addition, students have little interest in contributing to a discussion if no clear expectations are given or if no grades are awarded for their contribution in asynchronous online discussion. Dennen (2005) found that in cases where instructor expectations were not clear, student contribution floundered because students did not know how much they were to contribute or what their messages should look like. The results of Dennen's (2005) study also suggested that when no grade was attached to using the discussion forum many students did not post any messages during the whole semester. Heckman and Annabi (2006) argue that to increase student participation, students must also be held accountable for participation in discussions, which can be accomplished by assigning grades in accordance with the quality and frequency of their posting to the asynchronous discussion group. Without accountability, students are much less likely to participate in these discussion groups. While grades can motivate students to post, researchers suggest that instructors must establish clear expectations for student participation to ensure that students understand the desired levels of interaction, such as response time and frequency of participation. Dennen (2008) suggests that both demonstration of knowledge and student interaction are equally important when assessing quality of discussion posts. Thus, she asserts assessment rubrics for discussions should include the major activities performed by students during general content acquisition, which include "read (source documents, each other's messages), write (their own thoughts and conclusions), and engage with others (ask questions and provide feedback)" (p.210). Including these three items within a scoring rubric holds students accountable for all aspects of an

\section{4}


asynchronous discussion aimed at increasing general content acquisition.

In addition to holding students accountable, Gilbert and Dabbagh (2005) point out that the design of online discussion activities has a significant influence on the quality and frequency of student posts. Discussions should be instructor initiated (Ko et al., 2010), anchored in the content topic being covered in class, and interesting in nature. Andresen (2009) stresses that instructors should spend sufficient time in advance preparing carefully thought-out discussion questions that are stimulating and directly related to class subject matter. Bender (2003) describes a facilitator as one who enhances student learning by encouraging active participation in discussion and by helping to see the activity as meaningful and relevant. Next section presents the role of instructor and peer in enhancing participation.

\section{Facilitation in Online Discussion}

Many colleges and universities around the world have sought to increase student enrollments by expanding learning opportunities using online or blended courses (Hew, Liu, Bonk, \& Lee, 2004). However, it is not sufficient to merely place content on a web site for students to download materials or to complete online quizzes and assignments for an online or blended learning course to be successful. Contemporary discussions of education increasingly stress the social nature of learning (Palincsar \& Herrenkohl, 2002), which emphasizes interactions or discussions among students. Probably the major impetus behind the stress on social learning is the belief that interaction among students could generate additional activities such as explanation, disagreement, and knowledge sharing which could augment individual learning

\section{5}


Typically in an online or blended learning environment, students and instructors may interact with one another synchronously or asynchronously. However, the timeindependent nature of asynchronous discussion makes it particularly well received by many educators compared to synchronous discussion (Romiszowski \& Mason, 2004). One of the advantages of communicating at their own pace means that students who are shy, quiet, or who prefer more time to think before responding can have the opportunity to participate in the discussion. One important means to foster student participation is through online facilitation which can be done by an instructor (instructor facilitation) or by students (peer facilitation).

\section{Instructor Facilitation in Online Discussion}

Examining students' perceptions of these two forms of online facilitation (instructor and peer) is relevant and important because it can affect students' desire to participate in the online discussion. Previous research has identified student participation in online discussions as one of the activities that students found most beneficial to their learning (Ertmer, Richardson, Belland, Connolly, \& Coulthard, 2007; Richardson and Swan 2003). Students who participate in forums tend to receive higher grades and higher course retention rates (Coetzee, Fox, Hearst, \& Hartmann, 2014; Palmer, Holt, \& Bray, 2008; Yukselturk, 2010).

Traditionally, the instructor serves the role of an online facilitator. Examples of instructor facilitation include keeping the discussion on track, establishing ground rules and good discussant behavior, helping students overcome technical problems, and asking questions to help participants understand a particular issue or topic, or drawing students' attention to opposing perspectives (Yeh \& Lahman, 2007). However, recently, some scholars have

\section{6}


begun to question whether an instructor is the right candidate for the role or not (Arend, 2009; Correia \& Baran, 2010; Mazzolini \& Maddison, 2007; Seo, 2007; Zhao \& McDougall, 2005). Overall, there are two main concerns raised about an instructor being an online discussion facilitator.

First, facilitating an online discussion could be very time consuming as it requires the facilitator to read the posts, monitor any opinions that may be going off-track, answer students' questions, and ask appropriate questions to keep the discussion going. Consequently, not all instructors may be able to dedicate the amount of time and energy needed to facilitate the discussions properly (Seo, 2007). It seems to be no end to the demands on the instructor time and energy. Second, a discussion facilitated by an instructor may result in an instructor-centered discussion and limit students' participation and voice (Zhao \& McDougall, 2005). A majority of students felt nervous in expressing their opinions when the instructor was present in the discussion (Hew, Cheung, \& Ng, 2010). Many students also treated the discussion questions as short answer essay questions instead of interactive discussions when the discussion was facilitated by the instructor (Correia \& Baran, 2010). It seems that students were more interested to tell their instructor that they had posted something in the forum so that they would be noticed and, hopefully, gain a better participation mark or grade, rather than to exchange ideas with their peers. An instructor facilitated discussion could also lead the students to depend on the instructor to initiate, direct, and close the online discussions.

\section{Peer Facilitation in Online Discussion}

Therefore, it is not very surprising to hear some scholars advocating the use of students as facilitators of online discussions. Results of previous research on peer facilitation

\section{7}




\section{Number 74, June, 2016}

have suggested that students felt more comfortable expressing their views, brainstorming for ideas, and challenging one another's ideas in a peer-facilitated discussion environment (Baran \& Correia, 2009; Correia \& Davis, 2007; Cheung \& Hew, 2010; Rourke \& Anderson 2002). Rourke and Anderson (2002), for example, reported that a majority of students expressed a preference for peerfacilitated discussions over instructor facilitated ones, explaining that peer-facilitated discussions invited more responses. An instructor-facilitated discussion, on the other hand, may create an "authoritarian presence"' (Rourke \& Anderson, 2002, p. 4) that is not conducive to genuine conversation. Correia and Davis (2007) found that peer facilitation was the most popular collaboration design preferred by online learners.

The effects and usefulness of peer feedback on asynchronous online discussion boards have been explored. Ertmer et al. (2007) indicated that the use of peer feedback in an online learning environment presents a number of advantages such as: increasing the timeliness of feedback, providing new learning opportunities for both providers and receivers of feedback, humanizing the environment, and building community. La Pointe and Gunawarndena's (2004) study also indicated that student-student interaction has a higher impact on students' learning outcomes, than merely student-instructor interaction. Yet, the problem is that although student-student interactions are considered to be one of the critical key factors in fostering a successful learner-centered online learning environment, research suggests that they do not seem to occur voluntarily. Quite often, in fact, there are "lurkers," who may never participate (Farag, 2016). In particular, Khine, Yeap, and Lok (2003) studied the habits of teacher candidates' interactions on the $\mathrm{CMC}$, indicating that they seemed to

\section{8}


retain the habits of not actively participating and interacting, and that they did not continue prolonged asynchronous discussions. Furthermore, unless feedback among students was required, they did not seem to read other postings and respond to their peers. Similarly, it is noted that some students are not used to critiquing others' postings/thoughts/opinions, while many more are just too shy to post their own responses (Moore, 2002; Muilenburg $\&$ Berge, 2005). In these circumstances, requiring students to provide feedback to their peers' postings might be a necessary and productive strategy for facilitating asynchronous communicative activities. By requesting that learners submit constructive feedback to one another, instructors can enable learners to gain a greater comprehension of their peers' points of view. For example, when students found no peer response after their postings, Shin and Cho (2003) indicated that students felt their ideas were "ignored" and then "lost interest" in further posting activities. Additionally, they found that students were conscious of and concerned about where in the stream of discussion they should place their text. In other words, by engaging learners in this process, meaningful interaction may increase.

Many studies have specifically examined how an instructor's feedback impacted on student-student interactions, which is the primary of goal of this study as well. Wise, Hamman, and Thorson (2006) found that a moderated online discussion community by an instructor can elicit greater participation among students than an unmoderated one. Palloff and Pratt (2003) also suggested that the amount of instructor participation in the discussion impacted interactions among students. They asserted that the instructor should provide flexibility, and actively participate when initiating online discussions, until students

\section{9}


are capable of taking the responsibility to sustain them on their own. Once this is accomplished, however, the instructor should be careful about the amount of intervention, since too much intervention can possibly hinder the development of community.

\section{Research Gap and Needs for the Present Study}

There is a lack of agreement on the level of instructor intervention needed to effectively facilitate student participation and learning in asynchronous discussions. Expert opinions and available data on the impact of instructor intervention in asynchronous discussions are inconsistent and can depend on whether the focus of a discussion task is to promote participation (Pena-Shaff, Altman, \& Stephenson, 2005) or meaningful learning (De Wever, Schellens, Valcke, \& Van Keer, 2006; Marra, Moore, \& Klimczak, 2004). Some researchers suggest instructor presence and participation in asynchronous discussions improve student learning (Beaudoin, 2002; Brookfield \& Preskill, 2012; Muirhead, 2005; Walker, 2005) and increase participation (Bedi, 2008; Beadouin, 2002; Mandernach, Dailey-Hebert, \& Donnelli-Sallee, 2007). Contradictory research indicates that instructor participation in asynchronous discussions can neutralize or hinder student participation and learning (Andresen, 2009; Mazzolini \& Maddison, 2003; Swan \& Shih, 2005). Other researchers argue that instructor interventions in asynchronous discussions can be beneficial but only when used in moderation (Guldberg \& Pilkington, 2007; Heckman \& Annabi, 2006). Regardless of findings, the prevalent underlying assumption is that students have the potential to behave differently in online discussions based upon the presence or absence of instructor participation. With potentially conflicting research findings, a need for investigating the effect of the instructor participation in the online discussion on participation and learning. This

\section{0}


discrepancy in research findings suggests that participation in online discussion may be affected by individual differences such as gender and cognitive style, next section presents these two individual difference factors and their relations with participation.

\section{Gender Differences}

Whether gender plays a role in learning behaviors has been researched in both face-to-face and online learning environments. Gender differences have been identified in traditional classroom behaviors, online behavior, online discussions, social environments, stereotyping in classroom. This may mean that males and females have different strategies when processing information and interacting with other participants.

\subsection{Gender Difference in Different learning environments}

Despite the importance often assigned to participation in classroom discussions, it has been repeatedly found that most students do not participate (Caspi, Chajut, Saporta, \& Beyth-Marom, 2006; Crombie, Pyke, Silverthorn, Jones, \& Piccinin, 2003). For example, Crombie et al. (2003) reported that $64 \%$ of the students never, rarely, or only occasionally asked or responded to a question in the classroom. Caspi et al. (2006) recently reported that about $55 \%$ of the students never or rarely participated in class. Women avoid participation in classroom discussions more than men.

A large body of research is directed to gender differences in classroom behavior (Crombie et al., 2003; Sadker \& Sadker, 1994). The main finding is that females tend to speak less frequently and confidently than their male classmates. Instructors interact with male students more frequently, ask them better questions, and give them more precise and helpful feedback (Sadker \& Sadker, 1994). Although female students initiate more interactions than do

\section{1}


male students, male students receive more follow-up (Canada \& Pringle, 1995). In general, males dominate the classroom discussion. One leading explanation for the domination of males in classroom discussions is the "chilly climate" (Hall \& Sandler, 1984). This term relates to a cluster of kinds of systematic discrimination that disadvantage females in an academic environment. Crombie et al., (2003) gave the following examples that manifest such behavior: sexist use of language; presentation of stereotypic views of females; and instructors favoring male students. They noted that the existence of this construct was documented in many studies, though some did not find it. In comparison to participation in the face-to-face classroom, participation in the web-based instructional environment (WBIE) tends to be even lower (Caspi et al., 2006). Regarding the influence of gender on participation, some studies found equal participation of females and males in WBIE (Davidson-Shivers, Morris, \& Sriwongkol, 2003; Masters \& Oberprieler, 2004). However, other studies found gender differences either in the number of participants, type of participation, or dynamics of participation. It is noted that females have been found to enroll in online courses at a higher rate than males (Thompson, 1998). Arbaugh (2000) reported that females begin with a high level of participation that decreases over time and increases toward the end of the course, while males' participation is stable but on a moderate level. Barrett and Lally (1999) found that the mean length of messages sent to an online seminar by male students was, on average, more than twice as long as messages sent by female students. Sierpe (2001) found that a very small male minority dominated the conversational floor. In addition, regarding the type of participation, Sierpe reported that males were more likely to contribute to topical discussions and more likely to send multiple contributions to individual discussions. Yates (2001) concluded that

\section{2}




\section{Number 74, June, 2016}

gender differences found in face-to-face classrooms can also be found in WBIE with males engaging in similar tactics of exclusion and delegitimation. Like all communications media, web-based communication suffers from the intrusion of existing social relations, including those that are based upon inequalities of access and power.

Nevertheless, Gunn, McSporran, \& French (2003) found that females logged in, posted and read more messages than their male counterparts on the course bulletin board. Wolfe (2000) found that females were more likely than males to express a preference for the online format. Bostock and Lizhi (2005) reported that all-female groups posted more messages than all-male groups. In mixed-gender groups females posted more messages than males, but fewer than in all female groups. Males in mixed-gender groups posted more messages than in all-male groups. Bostack and Lihzi concluded that the presence of males deterred females' writing. However, Pollock, Hamann, and Wilson (2005) found that in balanced-gender groups, students of both sexes wrote longer messages, and posted more statements that signaled interaction with other participants. In addition, voices of female students were expressed more strongly in online than in face-to-face courses, and this contributed in turn to greater perceived deep learning (Anderson \& Haddad, 2005).

Thus, it is possible that the "chilly climate" did not migrate from the traditional face-to-face environment to the web-based environment. Other factors may be responsible for differences in participation of males and females in WBIE. First, males may perceive the purpose of learning via WBIE as an easy and economical way to learn, while females may view it as a way to increase collaborative learning (Arbaugh, 2000). In the same vein, GianniniGachago and Seleka (2005) reported that males asked

\section{3}




\section{Number 74, June, 2016}

questions and made statements more than females, while females responded more than males. If students hold different perceptions regarding the purpose of the environment, they may participate in different ways. Second, since it was claimed that females prefer webmediated learning, it is reasonable to expect that they would participate more in a web-based environment than in the face-to-face classroom.

\section{Gender Differences in Social Learning Environments}

Early psychological studies of the Internet focused on what was lost in text-based CMC. It was predicted that the reduction in social context cues through visual anonymity would greatly reduce the capacity to transmit social and interpersonal information (Sproull \& Kiesler, 1986). It was theorized that self-awareness was reduced in CMC. Thus, the 'cues-filtered out' approach (Sproull \& Kiesler, 1986) predicted that communication will be depersonalized, less 'social' and more uninhibited, in comparison to face-to-face communication. It was assumed that the medium only had the capacity to transmit task-oriented and cognitive material and not socio-emotional content. Socio-emotional content includes the use of emoticons, expressions of supporting references, self-references, references to others and selfdisclosure.

In contrast to the 'cues-filtered-out' approaches, Walther's (1992) social information processing theory maintained that text-based CMC could support socioemotional and relational communication. This theory assumes that CMC users are affected by the same internal drive of 'affiliation', i.e., interaction with other people, as participants in other communicative contexts. Therefore, it is suggested that CMC users will adapt existing communicative cues, within restrictions of language use and textual display, in order to convey relational

\section{4}


communication. However, a more recent theory of CMC known as the 'rational actor approach' (e.g., Markus, 1994), despite disputing the technological determinism of the 'cues-filtered-out' approach, is in keeping with it in terms of the proposed reduction in interpersonal communication. This has implications for the use of CMC in educational contexts as it suggests that students may be less responsive to the ideas of their peers during $\mathrm{CMC}$, questioning the extent of 'affective learning' (Biggs, 1987) that can occur in computer-mediated contexts. Gender may also influence the socio-emotional content of computer-mediated discourse.

Males are believed to value status more through the process of gender role socialization, whereas females are thought to value connection or affiliation more, leading to gender preferential communication styles, differentiated as 'competitive' and 'cooperative', respectively (Coates, 1993). Therefore, females may be more likely than males to express socio-emotional responses in CMC, such as expressing support and disclosing opinions, feelings and experiences. However, negative forms that would also qualify as responses to another's ideas, such as expressions of disagreement, are not always included in definitions of socio-emotional content.

It was suggested that the visual anonymity offered in text-based CMC would result in gender-free equality online and Graddol and Swan's (1989) findings supported this claim initially, as they found equal participation in an anonymous Open University conferencing system. However, this was later shown to be prematurely optimistic as Herring (1993) reported that males dominate online interaction by making longer and more frequent postings than females and subsequent studies, conducted in a variety of CMC contexts, supported this claim (Richardson \& French, 2000; Sierpe, 2000). Similar to face-to-face 
research, these results suggest that males dominate interaction, which may deter females from participating in CMC or force them to seek female-only groups online. Indeed, Yates (2001) suggested that altering the social context in the form of female-only online groups can moderate some of the problems experienced by female in educational interactions. However, gender segregation is neither practical, nor desirable, in an educational context. Furthermore, Miller and Durndell (2004) studied participation in an educational context and found that males and females were similar regarding quantitative measures of participation, as no significant gender differences were found in relation to the frequency or length of online postings. This was partly explained through the motivation to participate as marks were on offer for participation in this educational context and also because of the unequal gender balance, as females outnumbered males on the course. However, other studies have shown that relatively few males have still managed to dominate a discussion online (Light, Nesbitt, Light, \& Burns, 2000; Sierpe, 2000).

\section{Gender Difference and Stereotyping}

Gender stereotyping in the classroom begins as early as kindergarten, due to the influence of social norms (Marshall $\&$ Reinhartz, 1997). One reason why gender effects are clear is due to the effect of the instructor's gender. Men and women employ different teaching strategies that result in students learning differently. In general, male instructors tend to be more direct, subject-centered, and lecture more, while female instructors ask more student-centered questions and tend to use more indirect methods of instruction. This results in female instructors' classrooms being socially warmer with more opportunities for exploratory interactions. In contrast, male instructors' classrooms tend to be more authoritarian and controlled. 
In an ethnographic study, Keddie (2003) found that instructor perceptions of gender norms and differences influence how they interact with their students. Instructors who view boys' acting out behavior as being developmentally normal rather than problematic encourage and validate this type of behavior. Instructors are also unequal in how they create engagement in the classroom (Meehan, 2005). When the instructor is a male, female students do not respond as frequently, and male students participate more. Duffy, Warren, and Walsh (2001) added to these findings with their study, which found that male instructors direct equal attention to male and female students, while female instructors direct more attention to male students. Finally, an empirical study by Dee (2006) stated that male students are more disruptive in classrooms headed by women. In addition, he also found that in classrooms headed by male instructors, female students are more likely to say that they are not looking forward to the class and that they are afraid to ask questions. The same findings are true when male students are taught by female instructors. In order to prevent gender-stereotyped instruction from dominating the classroom, instructors need to examine their teaching methods and philosophies (Marshall \& Reinhartz, 1997). Care must be taken to invite nontraditional guest speakers of both genders who are equally successful and who can serve as roll-models. Instructors should also teach using multiple cooperative and competitive methods so that both male and female students benefit from the instruction. In particular, giving female students the opportunity to take leadership roles in the classroom helps to reduce gender bias.

\section{Gender Differences in Biological and Information Processing}

Many researchers believe that a large part of the explanations of why cognitive sex differences exist has to do with biology. Roughly, biological explanations can be

\section{7}


divided into three partially overlapping categories: the effect of sex hormones on the brain both before and after birth, genetic differences regarding sex and sexual orientations, and the specialization in the brain functions between men and women. For the purpose of this study, only the third explanation is discussed.

Studies on the function of brain focused mainly on the differences in lateralization during different types of tasks. Different parts of the brain were used for different spatial tasks (Hamilton, 1995). Males were seen to use their right hemisphere brain more than females, while females tended to use more of their left hemisphere brain than males. It was argued that the human brain is divided into two hemispheres and lateralization reflects the specialization in the function of each hemisphere: the left hemisphere specializes in verbal ability and the right hemisphere specializes in spatial perception. At some ages in development lateralization starts and the left hemisphere becomes dominant in its control over the individuals' behavior. It was argued that the timing of lateralization could affect development of both verbal and spatial ability. Developmental studies suggested that lateralization began earlier in girls thus giving them an advantage of verbal domain, while boys show superior spatial skills due to delayed in lateralization. It seemed that this explanation can account for the superiority of females on verbal tasks and males on spatially oriented tasks (Gaulin and Hoffman, 1988).

The way males and females process information was viewed as a main source of gender differences in performance on many subjects and spatial tasks. Focusing on information processing perspective to gender differences, Meyers-Levy (1989) suggested a model to explain the processing strategies adopted by each gender when facing information tasks. According to the model, gender

\section{8}


differences emerge because, under certain conditions, men are more likely to be driven by the overall message themes or schemas, and women are more likely to engage in detailed elaboration of messages. The model argued that men are 'selective processors' who often do not engage in comprehensive processing of all available information before giving responses. Instead, they seem to rely on various heuristics in place of detailed message elaboration. These heuristics involve a cue or cues that are highly available and salient and imply a particular inference (Darley and Smith, 1995). Such processing implies that men will often base their responses on a select subset of all available information. Therefore, they are more likely to filter information that is not relevant to the main theme. Women, on the other hand, are considered as 'comprehensive processors' who attempt to assimilate all available information before giving a final response. Women, according to the model, usually attempt effortful elaboration of all the available information unless they are restricted by memory constraints such as presentation time.

Based on this model, Meyers-Levy and her colleagues (Meyers-Levy, 1989; Meyers-Levy and Maheswaran, 1991; Meyers-Levy and Strenthal, 1991) made several predictions concerning how both genders approach the learning task. Some of these predictions are discussed within the context of the present study. The model predicted that when dealing with tasks, males adopt a selective (heuristic) method in processing. This type of method is guided by schemas and prior knowledge and expectations. Females, by contrast, are comprehensive processors who consider all aspects of information. Therefore, males should show superior recall for information that is consistent with the main theme and schema and filter out all other irrelevant information. Such selectivity of males should result in recalling

\section{9}




\section{Cognitive Style}

Designing instructional environments according to the user's needs has been the focus of instructional designers (Summerville, 1999; Raven, Cano, Garton, \& Shelhamer, 1993). Individual differences are related with how people are similar and how they are differ in their thinking, feeling and behavior. So educators and instructional designers have to attempt to understand and identify the influences of individual differences on learning to maximize the efficiency of instruction. The effects of individual differences on learning are examined through a large body of educational research. Due to these researches, some learning and/or cognitive styles have been classified over the years. One of the most well- known and accepted cognitive style is field dependence/field independence developed by Witkin, Moore, Goodenough, and Cox. (1977).

\section{What is Cognitive Style?}

The term cognitive style is used variously in the literature to refer to different things or different terminologies are used to describe the same thing (Riding and Rayner, 1998). A possible reason for this problem may be attributed to the fact that many cognitive style theories and models stemmed from different research traditions and this, as Messick (1994) argued, resulted in a fragmentation of understanding the construct of style among researchers. Riding and Cheema (1991) recognized the same problem, arguing that several researchers in psychology have worked on cognitive style but many of them have worked separately from the others. The results then many definitions and dimensions of styles have been suggested; many of these definitions are confounding styles and other constructs, and/or many others have different names but indicate the same thing. In order to

\section{0}


highlight this problem, some of the definitions that have been suggested to describe cognitive style are considered.

Cognitive style was defined by Sternberg (1997) as the preferred way of thinking and using abilities. Witkin (1950) referred to cognitive style as an individual's typical mode of cognition as reflected in the person's dispositions in perception. Witkin et al (1977) described style as the characteristic, self-consistent mode of functioning that individuals show in their perceptual and intellectual activity. Moran (1991) defined style as the manner in which people differ from each other in the way they process information from the world. Goldstein and Blackman (1978) referred to styles as the characteristic ways in which an individual conceptually organizes the environment. Kegan, Rosman, Day, Albert, Philips (1964) defined styles as the speed and accuracy of decision-making under uncertainty. Messick (1984) described styles as consistent individual differences in ways of organizing and processing information. Consistent with Messick, Tennant (1988) indicated that cognitive style is an individual's characteristic and consistent approach to organizing and processing information. Jonassen and Grabowski (1993) referred to styles as general tendencies to prefer to process information in different ways. Allinson (1992) indicated that styles are general habitual mode of processing information. Entwistle (1981) referred to style as the tendency of the individuals to adopt a particular strategy. Based on the aforementioned definitions, it seems difficult for a researcher to understand the nature of cognitive style since cognitive style was used interchangeably with learning style, ability, and learning strategies. Perhaps the most convenient definition of cognitive style was suggested by Riding and Rayner (1998, P.8) and Riding and Sadler-Smith (1997, P.199), that is, "an individual's consistent and habitual approach to organizing

\section{1}


and representing information". This latter definition will be used throughout the study.

According to Riding and Cheema (1991), the various labels of cognitive style theories can be categorized into two main dimensions. The first dimension is the WholistAnalytic style, of whether an individual tends to process information in whole or in parts. The second dimension is the Verbal-Imagery style, of whether an individual tends to represent information during thinking verbally or in mental images. This approach of considering cognitive style reflects an information processing perspective. The first dimension is the focus of the present study.

\section{Cognitive Style vs. Mental Ability}

The difference between cognitive style and mental ability has received considerable attention in the literature. One reason behind that are the contradictory results that emerged in school learning context in respect to the relationship between intelligence and achievement. This relation has not been in the expected direction. This might lead some researchers to argue that the relation between intelligence and achievement is likely to be moderated by other factors such as cognitive style (e.g., Riding and Agrell, 1997; Sternberg, 1997). With respect to instructional design, an understanding of the relation and differences between intelligence and cognitive style on one hand, and both and performance, on the other, can provide instructional designers with some guidelines to incorporate these elements in the design process.

Cognitive style and ability differ in many respects. Messick (1984) and Riding and Rayner (1998) identified some of these differences. First, ability is seen to refer to content, component process and level of cognition, whereas cognitive style reflects the manner of processing information. In this sense, ability is to answer a question of

\section{2}


what kind of information is being processed. It also reflects answers to questions of how much and how well information is being processed. On the other hand, cognitive style is considered to answer a question of how do we process information. Second, ability is unipolar while style is bipolar. Third, ability emphasizes maximal (level of) performance, while cognitive style focuses on the manner of performance in terms of either typical or contrasted performance. Fourth, ability has value attached to it, such that one end of an ability dimension is valued and the other is not, while for a style dimension neither end is considered better overall. Fifth, ability probably refers to specific content or functions such as verbal ability, numerical ability and so on. Cognitive style and mental ability are two distinctive constructs, which under some conditions can be highly correlated, but under other conditions can become independent. The relation mostly depends on the type of task.

\section{Cognitive Style vs. Learning Strategies}

Riding and Caine (1993) made a clear distinction between cognitive style and learning strategies. They argued that strategies might be learned and developed according to needs. Style, by contrast, is static and relatively in built features of the individual. To explain this point, Riding and Cheema (1991) stated that in the case of mismatch between style and learning situation, people might try to develop learning strategies to help them cope with tasks incompatible with their styles. An important aspect of developing strategies in learning in the case of mismatch between cognitive style and the requirements of the task is the conscious effort an individual use to translate information coded in a mode or structure which does not suit the individual's cognitive style. In summary, cognitive strategies are to minimize error during decision-making processes (Grigorenko and Sternberg, 1995). Thus, in order

\section{3}


for a subject to deal with a learning material, cognitive style affects how to organize, and represent information and whether the subject imposes structure on the material or accepts structure as presented, whereas learning strategies are likely to assist learners in developing learning relevant skills or provide a compensation for lacking processing operation.

Field Dependent (FD) and Field Independent (FI)

Perhaps the most intensively studied cognitive style is Field Dependence-Independence (FFI), originally proposed by Herman Witkin. FDI is a dimension that reflects the tendency of an individual to perceive entire fields as a whole (Field Dependence) or focus on isolable components of a field (Field independence). More specifically, Field Dependent individuals show a high degree of "dependence on the structure of the prevailing visual field", whereas Field Independent individuals deal with the presented field analytically" and mentally "separate an item from the configuration in which it occurs (Riding \& Rayner, 1998).

The concept of cognitive style known as Field dependence originated in laboratory studies on perception by Witkin and Asch (1948) and Witkin (1950). Witkin and his colleagues found that individuals differ "consistently on spatial orientation tasks from each other but that the properties of perceptual field alone could account for the variation" (Witkin \& Moore, 1974, P.8). The results of these studies revealed that individuals were different but consistent in their preferred modes of processing information. For example, Witkin and Moore (1974) used the term, Field Independence, to describe individuals who rely on an internal, vestibular frame of reference when locating an upright rod from a surrounding tilt frame in space. On the other hand, Field Dependence was applied to describe a person who relies on external, visual frame of

\section{4}


reference. After several experiments in laboratories, Witkin and his colleagues developed the Embedded Figure Test (EFT) followed by the Group Embedded Figure Test (GEFT) which was used in the present study but in its Arabic Version.

Overall, independent-dependent style dimension refers to the individual tendency to organize and process information either in a global way or in parts. In this sense, dependent learners process, perceive, treat, or see tasks as a unit, whereas independent learners process, perceive, treat or see tasks as a collection of parts. Dependent learners may find difficulty differentiating, discriminating between different aspects of the stimuli, while independent learners may find difficulty in perceiving, handling stimuli as a unit. Dependent learners perceive the stimuli as a unit, and the parts of the stimuli are different. Whereas independent learners perceive the stimuli as discrete parts but the whole view is less likely to be obtained. Sometimes dependents may find it difficult to discriminate between the parts of the stimuli to the degree that makes the parts be "blurred". As a consequence of that they may find it more difficult to gain the whole picture of a piece of information. For the independents, because they may focus on one aspect only of the whole at a time, the possibility of having distortion in their perception of the stimuli is expected. One aspect of the stimuli may become more prominent than the rest and as a consequence this part of the situation is exaggerated and get out of proportion with the total situation (Riding, 2002).

Messick (1976) summarized the characteristics of analytical and global dimensions such that "the fieldindependent pole includes competence in analytical functioning, combined with an impersonal orientation, while the field-dependent pole reflects correspondingly less competence in analytical function combined with greater

\section{5}

Journal of Arabic Studies in Education \& Psychology (ASEP) 
social orientation and social skills" (p. 14). In the psychological dimension of cognitive style, Saracho (2001) summarized that field-dependent individuals usually rely on the surrounding field and authority to make their decisions. They observe the faces of those around them for information, prefer to be with people, and experience their environment in a relatively global fashion as they conform to the prevailing field or context. Saracho also stated that "field-independent persons tend to be able to abstract elements from the surrounding field and to solve problems identifying critical elements out of context, remaining socially detached, independent of authority, and analytic" (p.197). He concluded that field-independent individuals have more advantages than field-dependent individuals in logical thinking and problem-solving skills. Field-dependent individuals are more sensitive to social cues, and fieldindependent individuals are more independent in decisionmaking and more competitive in social interaction.

\section{Cognitive Style and Learning Environment}

Traditionally, educators have believed that there is one particular instructional method that is most appropriate to learning a certain subject. This requires each student to adapt as best as he or she can to the instructional method being used. It is common knowledge that students have differences in their cognitive style to handle information delivered by a particular instructional method, as well as in their style to handle a particular subject. Students seek and process information using very different strategies. Those who can best adapt to the instructional method will have the best chance for academic success.

Studies examining cognitive styles have shown field dependency to be a significant characteristic influencing how individuals interact and perform in different learning environments (Carrier, Davidson, Higson, \& Williams,

\section{6}


1984; Hannafin, 1984). Students with different cognitive styles leam differently. According to Riding and Rayner (1998), field-independent learners adopt an active approach toward learning while field- dependent learners adopt a passive approach. In educational situations, field-dependent students prefer feedback and social sources of information (Jones, 1999), which can be found in a classroom environment. Field-independent students are generally expected to perform better academically than those who are field-dependent, and this is particularly true in an environment where students learn without the support offered by a traditional classroom. It is meaningful for educators to understand the relationship between student cognitive styles and different learning environments and their impact on learning.

Field-dependent and field-independent students react to classroom learning differently. In a traditional classroom, teachers and students are engaged in a continuous, interactive dialogue. Interaction between teachers and students is influenced by characteristics of both teachers and students. Cognitive style affects student classroom participation and activities. In traditional classroom activities, students are often presented with problem-solving activities integrated with concept learning. Field independent learners, being more analytically prone, enjoy the challenge. Field independent learners are more successful in the traditionally structured learning environment because it rewards analytical thinkers who are capable of working independently. Field-dependent learners, on the other hand, experience greater difficulty with problems that require analytical thinking (Morgan, 1997); they would depend more on teachers' guidance. Studies also show that field-dependent learners demonstrate less structuring ability than field-independent learners in a

\section{7}


classroom situation (Witkin \& Goodenough, 1977). Fielddependent students display certain distinctive characteristics, such as depending on and being influenced by "authority figures." Also they are less able than fieldindependent students to generate alternative functions for elements or items used in a familiar way (Witkin \& Goodenough, 1981).

\section{Social Presence}

In recent years, online environments have become more widely used for teaching courses and for affording interactions between learners and instructors. One important aspect of an online learning environment is the ability of the learners to establish a satisfying level of social presence. Online environments, and especially text-based environments, may challenge the process of constructing social presence, which in turn may impair learning processes. With the online environment, it is now possible to create flexible online learning environments without time and distance barriers. These environments enable learners to access materials, share ideas, and discuss with other participants online (Chen, Kinshuk, Wei, \& Yang, 2008; Traphagan, Kucsera, \& Kishi, 2010). However, learners are likely to have negative experiences of isolation because of their physical separation from other participants (Rovai 2007). These negative experiences can be reduced or eliminated by enhancing perceived social presence of learners (Rovai 2007).

\section{Social Presence: A Conceptual Framework}

Social Presence and Quality of a Medium: The foundation of social presence originated in telecommunication research. Short, William, and Christie (1976) initiated the concept of social presence and defined it as "the degree of salience of the other person in the interaction and the consequent salience of the interpersonal relationships" (p.65). According to Short et al., social

\section{8}


presence is a quality of medium itself and is based on the capacity of media to convey vocal and non-verbal information (i.e. facial expression, gesture, physical proximity) in face-to-face communications. They argued that communication media vary in the degree of social presence and that text-based media which lack cues (e.g. eye contact, facial expression, voice intonation) are cold and impersonal and rate low in social presence. Based on this notion, asynchronous text-based communication with a lack of nonverbal and vocal communication cues has low social presence so it cannot transmit the social and contextual information necessary to sustain learning (Swan and Shea, 2005, p. 8).

Social presence constructed was thought to be back to the concept of immediacy in traditional face to face learning. Immediacy was defined as those communication behaviors that enhance closeness to and nonverbal interaction with another (Caspi \& Blau, 2008). According to Caspi and Blau, nonverbal communication leads to more immediate interaction and psychological closeness, while a conversation that lacks cues such as gestures or facial expression will result in a "distant" interaction. The concept of immediacy has been tested widely in face to face classes (Witt, Wheeless, \& Allen, 2004), mainly as a factor that relates to teacher-student relationships. Short et al. (1976) elaborated upon these ideas and hypothesized that the inability of a communication medium to transmit nonverbal cues has a negative effect on interpersonal communication. They defined social presence as "the salience of the other in a mediated communication and the consequent salience of their interpersonal interactions" (p. 65). In other words, if a communicator does not intimately perceive her partner as a real person while communicating via a specific medium, this medium is said to be impersonal, cold and unsociable.

\section{9}


Social Presence as Self-projection: Researchers in the field of online learning, however, have challenged the assumption that asynchronous text-based communication lacks cues and provides evidence that participants in online situations have developed the ability to create textual and linguistic behaviors as a means to compensate for the lack of social and nonverbal cues (Rourke, Anderson, Garrison, Archer, 2001; Swan, 2003; Garrison \& Anderson, 2003; Shih and Swan, 2005). As Garrison and Anderson (2003) noted, "students can and do overcome the lack of non-verbal communication by establishing familiarity through the use of greetings, encouragement, paralinguistic emphasis (e.g., capitals, punctuation, emoticons), and personal vignettes (i.e., self-disclosure).

In the online learning context, social presence is viewed as social behavior in mediated communication rather than the capacity of media, and is redefined as "the ability of participants in a community of inquiry to project themselves socially and emotionally, as 'real' people (i.e., their full personality), through the medium of communication being used" (Garrison, et al., 2000, p. 94). In other words, social presence is "the ability of participants to project themselves socially and emotionally in a community of inquiry" (Rourke et al., 2001, p. 4). This definition differs from the previous one in three senses: First, Garrison and Anderson (2003) moved the focus from the potential of a medium to allow communication that affords transmission of social cues, to the actual communication observed. Second, while Short et al. (1976) focused on the limitations that a medium imposes on the interaction, Garrison and Anderson focused on the way people overcome these constraints. Third, and perhaps more important, instead of focusing on how people perceived the other(s) they considered "social presence" as projection of the self. Perception of other and selfprojection are two independent processes. Moreover, since perception is a subjective process, it is quite possible that,

\section{0}


despite the projection of someone's self onto an online community, the other participants do not necessarily perceive her as a "real" person. Blau and Caspi (2007) found evidence that there is a discrepancy between the way people perceive the level of social presence in a text-based discussion group and the level that is uncovered by counting textual projections of participants' self within that group. Swan and Shih (2005) found that the perception of social presence is related to its presentation: Students perceiving the greatest presence of others in online discussions also consistently projected more of their own self therein.

Social presence as Social Identification of a Group: A third conceptualization of social presence was suggested by Rogers and Lea (2005). According to Rogers and Lea (2005) a feeling of belongingness to a group, or identification with a group, can occur even in a "lean" environment that supplies minimal social cues. Moreover, such feelings may result in a perceptual immersion within the group. Rogers and Lea (2005) conceptualized social presence as a feeling of belongingness to, and identification with, an online group that causes this sense of immersion.

Overall, a literature review disclosed three different conceptualizations of social presence that were studied in learning contexts: (1) as a characteristic of a medium that enables (or disables) transmissions of social cues that are essential to perceive another learner as "real"; (2) as the potential for a learner to project himself socially and emotionally as real people in an online community, and (3) as a characteristic of a group, that reflects the level of social identification with, and the sense of belongingness to an online learning group.

\section{Social Presence Categories and Indicators}

Based on Garrison et al.'s Community of Inquiry model (2000), three analytical categories of social presence were outlined: (1) expression of emotion, (2) open communication, and (3) group cohesion. Expression of 
emotion, specifically, "the ability or confidence to express feelings related to educational experience" (Garrison, Anderson, Archer, 2000, p. 99), consists of emoticons, humor, and a sharing of feelings, attitudes, experiences, and interests" (p. 100). In an online discussion, affective responses convey "respectful and supportive socioemotional responses" (p. 52) that facilitates participants engaging in meaningful discussions necessary for critical thinking. In addition, "affective responses have a direct effect on interactivity and open communication" (Garrison and Anderson, 2003, p.52). Open communication is defined as "reciprocal and respectful exchanges" (Garrison et al., 2000 , p. 100) comprised of (1) mutual awareness (the interactive behavior that builds group cohesiveness, i.e. using the reply feature, quoting directly, directing a comment to a particular person, and referring explicitly to others' messages); and (2) recognition of individual contributions (i.e. expressing appreciation and agreement, complimenting others, and encouraging others). According to Garrison and Anderson (2003), open communication "reflects a climate of trust and acceptance" (p. 52) of the participants in online learning environments and is concerned with responding and contributing to other's textual interactions in online learning. Group cohesion is "focused collaborative communication that builds participation and empathy" and "is exemplified by activities that build and sustain a sense of group commitment" (Garrison et al, 2000, p. 101). It has also been identified as "cohesive responses" which are "essential to sustain the commitment and purpose of a community of inquiry, particularly in an e-learning group separated by time and space" (p. 53). Cohesive responses are built by addressing other group members by their names, or by using inclusive pronouns such as 'we' and 'our' (p.53).

\section{RESULTS \& FINDINGS}

This section presents the data analysis and results for the research questions of the study, and so the results will be

\section{2}


presented in terms of the determined questions. The results are presented in two sections as follow.

\section{SECTION ONE: EFFECTS OF INDEPENDENT VARIABLES}

\section{SECTION TWO: EFFECTS OF INTERACTION}

\section{SECTION ONE: EFFECTS OF INDEPENDENT VARIABLES}

\section{Answering the First Question}

The first question of the study states: What is the effect of the Instructor presence in online discussion on participation, learner's perceived social presence and Quality of Scientific research writing? Question one addressed whether the presence of instructor in online discussion impacted participation, perceived social presence and quality of writing a scientific paper. Students in the first discussion group received continuing feedback from the instructor during the discussion on the questions posted in the forum and students were requested to respond to the questions and comment on their peers' ideas or the instructor postings. In the second discussion group, the same questions posted in the discussion without interventions from the instructor and requested to comment and discuss with their peers on the topic of questions. Because the first question of the study addressed instructor interventions with respect to participation, social presence and quality of writing a scientific paper, the results will be detailed in three sections as follow:

\section{Instructor Interventions by participation}

Instructor Interventions by Amount of Participation

The sample of the study consisted of fifty two postgraduate Mater of Information and Communication Technology in Education Students who studied a course titled: Scientific Research Method Course. The Course was

\section{3}


Web-enhanced. Of the 52, 26 students received moderate instructor interventions during the online discussions, with 6-8 postings from the instructor each week on the topic and question posted in the course forum. The second group received no postings from the instructor but peers feedback and student-student interaction was the condition. Table 2 shows the descriptive statistics for both treatment groups.

Table 2: Frequencies and percentages of postings by instructor interventions

\begin{tabular}{|c|c|c|c|}
\hline $\begin{array}{c}\text { Instructor } \\
\text { Intervention }\end{array}$ & $\mathrm{N}$ & $\begin{array}{c}\text { Response } \\
\text { Frequency }\end{array}$ & $\begin{array}{c}\text { Percentage of Total } \\
\text { Responses }\end{array}$ \\
\hline Instructor Postings & 26 & 488 & $46.2 \%$ \\
\hline $\begin{array}{c}\text { No Instructor } \\
\text { Postings }\end{array}$ & 26 & 568 & $53.8 \%$ \\
\hline
\end{tabular}

Table 2 indicates that the frequency of postings by the no instructor group is higher than the instructor postings group. The mean number of postings posted by student in each group is presented in Table 3.

Table 3: Means and standard deviations of discussion responses by instructor interventions

\begin{tabular}{|c|c|c|c|}
\hline Instructor Intervention & $\mathrm{N}$ & $\mathrm{M}$ & $\mathrm{SD}$ \\
\hline Instructor Postings & 26 & 18.73 & 1.69 \\
\hline No Instructor Postings & 26 & 21.85 & 2.60 \\
\hline
\end{tabular}

Table 3 shows that the mean number of postings by individual student is higher in the absence of instructor than in the presence of instructor. In order to estimate whether the difference in mean scores showed also a significant effect, an ANOVA was conducted, and the results of the Analysis is presented in Table 4.

Table 4: The between subject effect of instructor interventions by number of

\begin{tabular}{|c|c|c|c|c|c|}
\hline & $\begin{array}{c}\text { Sum of } \\
\text { Squares }\end{array}$ & df & Mean Square & F & Sig. \\
\hline Between Groups & 126.173 & 1 & 126.173 & 26.231 & .000 \\
\hline Within Groups & 240.500 & 50 & 4.810 & & \\
\hline Total & 366.673 & 51 & & & \\
\hline
\end{tabular}

The results of the between subject effect as shown in Table 4 indicates that there is a main effect of instructor 
intervention $(F=8.222 ; d f 1,50 ; P<0.001)$ on student's mean number of postings, with the no instructor postings condition $(\mathrm{M}=21.85, \mathrm{SD}=2.60)$ having more responses than the instructor postings group $(\mathrm{M}=18.73, \mathrm{SD}=1.69)$, and this is shown in Fig. 1.

\section{Instructor Interventions by Types of Participation}

When the instructor intervention involved by types of participation, the results showed that no instructor intervention group produced more on-topic and off-topic responses than the instructor intervention group, and these results are presented in Table 5.

Table 5: Number of responses and percentage of on topic and off topic codes

by instructor guidelines

\begin{tabular}{|c|c|c|c|c|c|}
\hline $\begin{array}{c}\text { Instructor } \\
\text { Intervention }\end{array}$ & $\begin{array}{c}\text { No. of On } \\
\text { Topic } \\
\text { Responses }\end{array}$ & $\begin{array}{c}\text { No. of Off } \\
\text { Topic } \\
\text { Responses }\end{array}$ & $\begin{array}{c}\text { Percentage of No. } \\
\text { of On Topic } \\
\text { Responses }\end{array}$ & $\begin{array}{c}\text { Percentage of No. } \\
\text { of Off Topic } \\
\text { Responses }\end{array}$ & N \\
\hline Instructor & 261 & 227 & $53.5 \%$ & $46.5 \%$ & 26 \\
\hline No Instructor & 274 & 294 & $48.2 \%$ & $51.8 \%$ & 26 \\
\hline
\end{tabular}

On topic and off topic responses were recorded and analyzed based on a rubric designed for this purpose. When inspecting Table 5, it can be seen that there was a slightly difference in number of off-topic and on-topic responses between the two treatment groups. A total of 1056 codes appeared with both groups, with 568 postings being shown for the no instructor discussion group but 488 appeared with the instructor intervention group. The no instructor postings group posted more off-topic responses than the instructor intervention group but the reverse was true for the presence of instructor group, with the on-topic postings being higher. In order to see whether the differences in number of ontopic and off-topic responses really show a difference in mean score of posting by student, an ANOVA was conducted with the off-topic and on-topic postings as the dependent variables. The results of the ANOVA are shown in Table 6. 
Table 6: The between subject effect of the on-topic/off topic responses by instructor intervention

\begin{tabular}{|r|r|l|l|l|c|c|}
\hline \multicolumn{2}{|c|}{} & Sum of Squares & Df & Mean Square & F & Sig. \\
\hline On & Between & 3.250 & 1 & 3.250 & 0.111 & .740 \\
\cline { 2 - 7 } Topic & Within & 1461.423 & 50 & 29.228 & & \\
\cline { 2 - 7 } & Total & 1464.673 & 51 & & & \\
\hline Off & Between & 86.327 & 1 & 86.327 & 1.896 & .175 \\
\cline { 2 - 7 } Topic & Within & 2276.654 & 50 & 45.533 & & \\
\cline { 2 - 7 } & Total & 2362.981 & 51 & & & \\
\hline
\end{tabular}

A Post hoc comparison of Tukey test (based on an alpha of .05) revealed that with respect to the on-topic postings, the no instructor intervention group ( $\mathrm{M}=10.04, \mathrm{SD}=5.33)$ had no difference than the instructor intervention group $(\mathrm{M}=10.04, \mathrm{SD}=5.48)$. For the off-topic responses, the no instructor group $(\mathrm{M}=11.31, \mathrm{SD}=7.43)$ produced the same off-topic postings as the instructor intervention group $(\mathrm{M}=8.73, \mathrm{SD}=5.99)$. This finding is shown in Fig. 1.

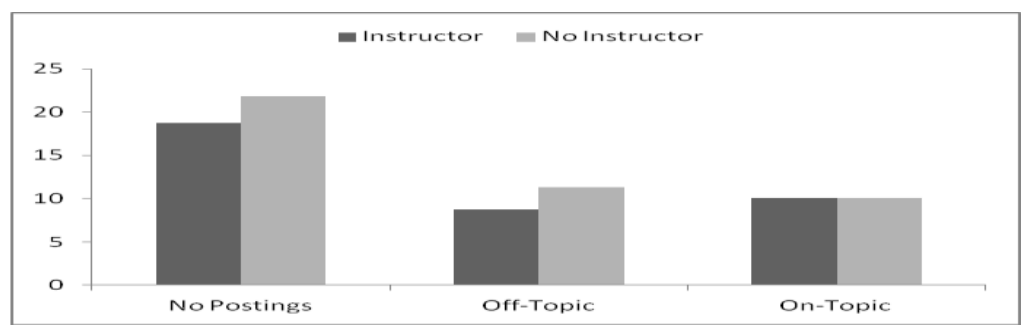

Fig.1: Main effect of instructor intervention by amount and types of participation in online discussion

\section{Instructor Interventions by Perceived Social Presence}

Participants were given a 30-item social presence scale after participating in the online discussion. A Likert-type scale of five possible responses, spanning from strongly agree to strongly disagree, was used. The scale for four questionnaire items (item seven, eight, twenty four and twenty six) were reversed to maintain consistency in the scales of the variables. The Cronbach's Alpha for the questionnaire items was 81 . The average mean score for the social presence scale $(\mathrm{M}=3.74, \mathrm{SD}=0.85)$, showed that, overall, participants had high social presence in online

\section{6}


discussions. The $95 \%$ confidence interval for this mean was 3.551 to 3.932. Therefore, overall participant social presence would be positive.

When the analysis involved instructor intervention by participant's perceived social presence, the one way ANOVA showed a main effect of the instructional condition $(F=28.220 ; \quad d f 1,50 ; \quad P=0.00)$, with the no instructor intervention group ( $\mathrm{M}=4.245, \mathrm{SD}=0.512)$ having higher perceived social presence than the instructor presence group $(\mathrm{M}=3.238, \mathrm{SD}=0.819)$, and this is shown in Table 7 and Fig.2.

Table 7: the between subject effect of perceived social presence by instructor intervention in online discussion

\begin{tabular}{|r|l|l|l|l|l|}
\hline & $\begin{array}{c}\text { Sum of } \\
\text { Squares }\end{array}$ & \multicolumn{1}{c|}{ Df } & Mean Square & F & Sig. \\
\hline Between Groups & 13.160 & 1 & 13.160 & 28.220 & .000 \\
\hline Within Groups & 23.318 & 50 & .466 & & \\
\hline Total & 36.478 & 51 & & & \\
\hline
\end{tabular}

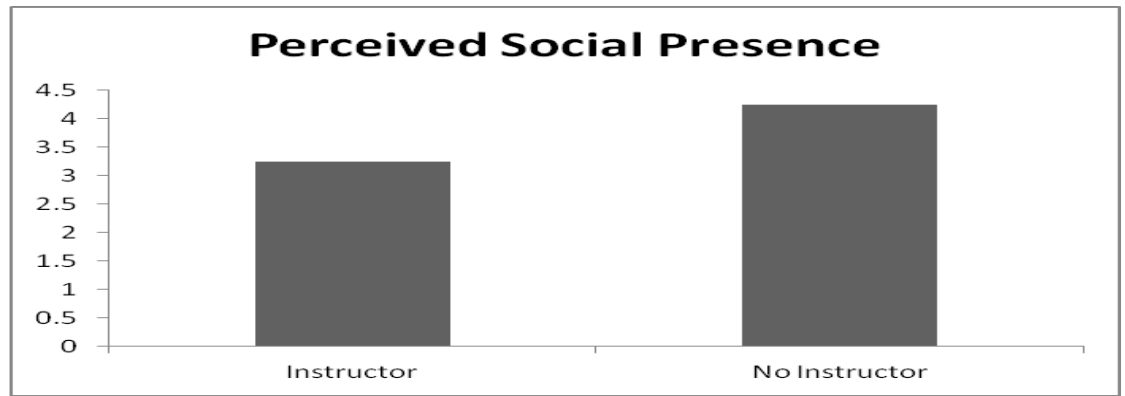

Fig.2: Main effect of instructor intervention by learner perceived social presence in online discussion

Instructor Interventions by Quality of Scientific Research Writing

Student skills for writing a scientific research were measured through writing a paper. Participants were requested to submit an experimental research paper for evaluation from three specialized professor in educational technology. The paper was evaluated based on a rubric designed for this purpose. The rubric consisted to ten sections beginning from evaluated the title of the paper 


\section{Number 74, June, 2016}

through the abstract, introduction to the conclusion of the paper. Each section in the rubric was designed to give students' scores based on analysis of the paper contents by the expert to see to what the extent each paper section covers the standards and indicators. Overall scores for the rubric was 100. The rubric ranged from excellent (paper writing meets or exceeds the standards) to satisfactory or unsatisfactory to unexpected.

The average mean score for the scientific paper writing rubric $(\mathrm{M}=58.90, \mathrm{SD}=16.61)$, showed that, overall, participants had satisfactory level of writing a scientific paper. The $95 \%$ confidence interval for this mean was 54 to 63.81. Therefore, overall participant scientific writing skills would be moderate.

When the analysis involved instructor intervention by participant's scientific paper writing, the one way ANOVA showed a main effect of the instructional condition $(F=12.009 ; \quad d f 1,50 ; P=0.001)$, with the no instructor intervention group $(\mathrm{M}=66.58, \mathrm{SD}=14.58)$ having higher skills in writing the scientific paper than the instructor presence group (M=51.23, $\mathrm{SD}=17.24)$, and this is shown in Table 8 and Fig.3.

Table 8: the between subject effect of quality of research writing by instructor intervention in online discussion

\begin{tabular}{|r|l|l|l|l|l|}
\hline & \multicolumn{1}{|c|}{$\begin{array}{c}\text { Sum of } \\
\text { Squares }\end{array}$} & \multicolumn{1}{c|}{ Df } & $\begin{array}{c}\text { Mean } \\
\text { Square }\end{array}$ & F & Sig. \\
\hline Between Groups & 3061.558 & 1 & 3061.558 & 12.009 & .001 \\
\hline Within Groups & 12746.962 & 50 & 254.939 & & \\
\hline Total & 15808.519 & 51 & & & \\
\hline
\end{tabular}

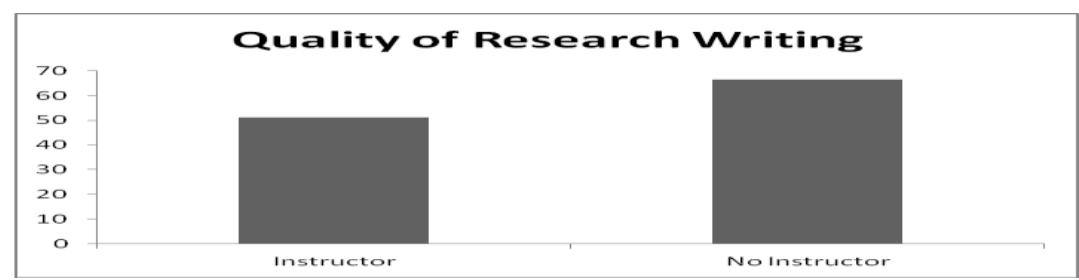

Fig.3: Main effect of instructor intervention by learner's quality of research writing 


\section{Answering the Second Question}

The second question of the study states: What is the effect of gender type on participation in online discussion, learner's perceived social presence and quality of scientific research writing? This type of question is presented in three sections based on the dependent variable as follows.

\section{Gender Type by participation}

\section{Gender Type by Amount of Participation}

The sample of the study included male and female participants. 27 male students participated in the first online discussion group while 25 females formed the second group of participants. The frequency of responses by males and females and percentage of responses are presented in Table 9.

Table 9: Frequencies and percentages of postings by gender type

\begin{tabular}{|c|c|c|c|}
\hline Gender Type & $\mathrm{N}$ & $\begin{array}{c}\text { Response } \\
\text { Frequency }\end{array}$ & $\begin{array}{c}\text { Percentage of Total } \\
\text { Responses }\end{array}$ \\
\hline Males & 27 & 584 & $55.3 \%$ \\
\hline Females & 25 & 472 & $44.7 \%$ \\
\hline
\end{tabular}

Table 9 indicates that the frequency of postings by the male students is higher than the females' frequencies of postings. The mean number of postings posted by student in each gender type is presented in Table 10.

Table 10: Means and standard deviations of discussion responses by gender type

\begin{tabular}{|c|c|c|c|}
\hline Gender Type & $\mathrm{N}$ & $\mathrm{M}$ & SD \\
\hline Males & 27 & 21.63 & 3.002 \\
\hline Females & 25 & 18.84 & 1.143 \\
\hline
\end{tabular}

Table 10 shows that the mean number of postings by male student is higher than in the mean number of postings by female student. In order to estimate whether the difference in mean scores showed also a significant effect, an ANOVA was conducted, and the results of the Analysis is presented in Table 11. 
Table 11: The between subject effect of gender type by number of postings

\begin{tabular}{|r|l|l|l|l|l|}
\hline & $\begin{array}{c}\text { Sum of } \\
\text { Squares }\end{array}$ & df & Mean Square & F & Sig. \\
\hline Between Groups & 101.017 & 1 & 101.017 & 19.013 & .000 \\
\hline Within Groups & 265.656 & 50 & 5.313 & & \\
\hline Total & 366.673 & 51 & & & \\
\hline
\end{tabular}

The results of the between subject effect as shown in Table 10 indicates that there is a main effect of gender type $(F=19.013 ;$ df 1,$50 ; P<0.000)$ on student's mean number of postings, with the males $(\mathrm{M}=21.63, \mathrm{SD}=3.002)$ having more responses than the females $(\mathrm{M}=18.84, \mathrm{SD}=1.143)$, and this is shown in Fig. 4.

\subsection{Gender Type by Types of Participation}

When the gender type involved by types of participation, the results showed that male subjects produced more offtopic responses than female students whereas females produced more substantive related on-topic responses than males, and these results are presented in Table 12.

Table 12: Number of responses and percentage of on topic and off topic codes by instructor guidelines

\begin{tabular}{|c|c|c|c|c|c|}
\hline $\begin{array}{c}\text { Gender } \\
\text { Type }\end{array}$ & $\begin{array}{c}\text { No. of On } \\
\text { Topic } \\
\text { Responses }\end{array}$ & $\begin{array}{c}\text { No. of Off } \\
\text { Topic } \\
\text { Responses }\end{array}$ & $\begin{array}{c}\text { Percentage of No. } \\
\text { of On Topic } \\
\text { Responses }\end{array}$ & $\begin{array}{c}\text { Percentage of No. } \\
\text { of Off Topic } \\
\text { Responses }\end{array}$ & N \\
\hline Males & 151 & 433 & $25.86 \%$ & $74.14 \%$ & 27 \\
\hline Females & 384 & 88 & $81.36 \%$ & $18.64 \%$ & 25 \\
\hline
\end{tabular}

When inspecting Table 12, it can be seen that there was a total of 1056 codes appeared with both groups, with 584 postings being shown for the male discussion group but 472 appeared with the female group. The male group posted more off-topic responses than the female group but the reverse was true for the female group, with the on-topic postings being higher. Three quarter of postings for the males were off-topic while more than three quarter of the female postings were on-topic. In order to see the significant differences between both males and females, an ANOVA was conducted, and the results are shown in Table 13. 
Table 13: The between subject effect of the on-topic/off topic responses by gender type

\begin{tabular}{|c|c|c|c|c|c|c|}
\hline \multicolumn{2}{|c|}{} & $\begin{array}{c}\text { Sum of } \\
\text { Squares }\end{array}$ & Df & $\begin{array}{c}\text { Mean } \\
\text { Square }\end{array}$ & F & Sig. \\
\hline \multirow{2}{*}{$\begin{array}{c}\text { On } \\
\text { Topic }\end{array}$} & Between & 1238.395 & 1 & 1238.395 & 273.644 & 0.000 \\
\cline { 2 - 7 } & Within & 226.279 & 50 & 4.526 & & \\
\cline { 2 - 7 } & Total & 1464.673 & 51 & & & \\
\hline \multirow{2}{*}{$\begin{array}{c}\text { Off } \\
\text { Topic }\end{array}$} & Between & 2058.889 & 1 & 2058.889 & 338.531 & 0.000 \\
\cline { 2 - 7 } & Within & 304.092 & 50 & 6.082 & & \\
\cline { 2 - 7 } & Total & 2362.981 & 51 & & & \\
\hline
\end{tabular}

A Post hoc comparison of Tukey test (based on an alpha of .05) revealed that with respect to the on-topic postings, the female group $(M=15.36, S D=1.68)$ outperformed the male group $(M=5.59, \quad S D=2.47)$. For the off-topic responses, the reverse was shown with the male group $(M=16.07, S D=2.84)$ outscored the female group $(M=3.48$, $S D=1.98)$. This finding is shown in Fig. 4.

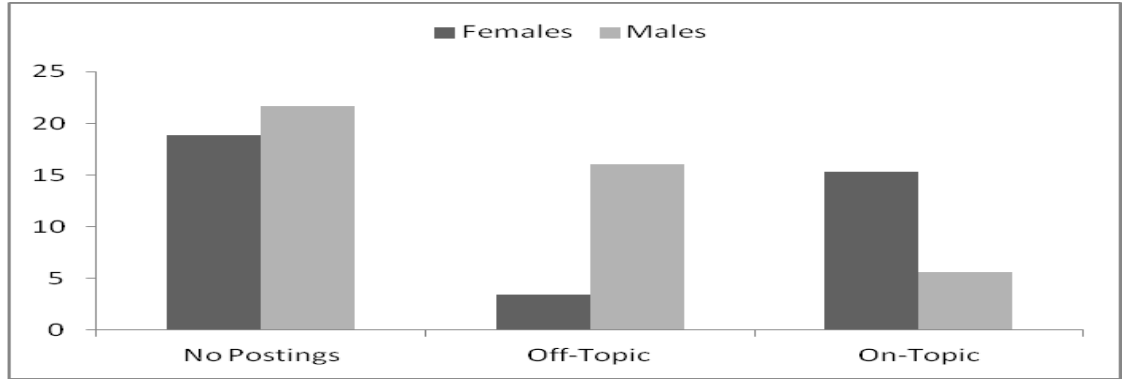

Fig.4: Main effect of gender type by amount and types of participation in online discussion

\section{Gender Type by Perceived Social Presence}

The average mean score for the social presence scale $(\mathrm{M}=$ 3.74, $\mathrm{SD}=0.85$ ), showed that, overall, participants had high social presence in online discussions. The $95 \%$ confidence interval for this mean with female and male students was 3.610 to 3.922. Therefore, overall participant social presence for males and females would be positive.

When the analysis involved gender type by participant's perceived social presence, the one way ANOVA showed a main effect of the gender $(F=66.899$; $d f 1,50 ; P=0.00)$, 
with the female group $(\mathrm{M}=4.4, \mathrm{SD}=0.38)$ having higher perceived social presence than the male group $(\mathrm{M}=3.74$, $\mathrm{SD}=0.85)$, and this is shown in Table 14 and Fig.5.

Table 14: The between subject effect of the perceived social presence by gender type

\begin{tabular}{|c|c|c|c|c|c|}
\hline & $\begin{array}{c}\text { Sum of } \\
\text { Squares }\end{array}$ & df & $\begin{array}{c}\text { Mean } \\
\text { Square }\end{array}$ & F & Sig. \\
\hline Between Groups & 20.876 & 1 & 20.876 & 66.899 & .000 \\
\hline Within Groups & 15.602 & 50 & .312 & & \\
\hline Total & 36.478 & 51 & & & \\
\hline
\end{tabular}

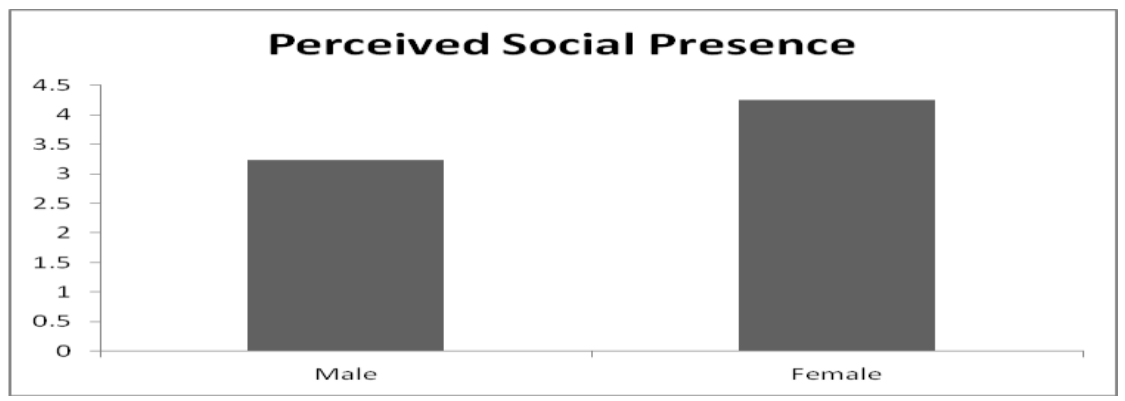

Fig.5: Main effect of gender type by perceived social presence in online discussion

\section{Gender Type by Quality of Scientific Paper Writing}

The average mean score for the scientific paper writing rubric $(\mathrm{M}=58.90, \mathrm{SD}=17.61)$, showed that, overall, participants had satisfactory level of writing a scientific paper. The $95 \%$ confidence interval for this mean with respect to male and female was 54 to 63.80 . Therefore, overall participant scientific writing skills would be moderate.

When the analysis involved gender type by participant's scientific paper writing, the one way ANOVA showed a main effect of the gender $(F=71.399 ; d f 1,50 ; P=0.000)$, with the female group $(\mathrm{M}=72.80, \mathrm{SD}=7.95)$ having higher skills in writing the scientific paper than the male group $(\mathrm{M}=46.04, \mathrm{SD}=13.86)$, and this is shown in Table 15 and Fig.6. 
Table 15: The between subject effect of quality of research writing by gender type in online discussion

\begin{tabular}{|c|c|c|c|c|c|}
\hline & $\begin{array}{c}\text { Sum of } \\
\text { Squares }\end{array}$ & df & Mean Square & F & Sig. \\
\hline Between Groups & 9297.556 & 1 & 9297.556 & 71.399 & .000 \\
\hline Within Groups & 6510.963 & 50 & 130.219 & & \\
\hline Total & 15808.519 & 51 & & & \\
\hline
\end{tabular}

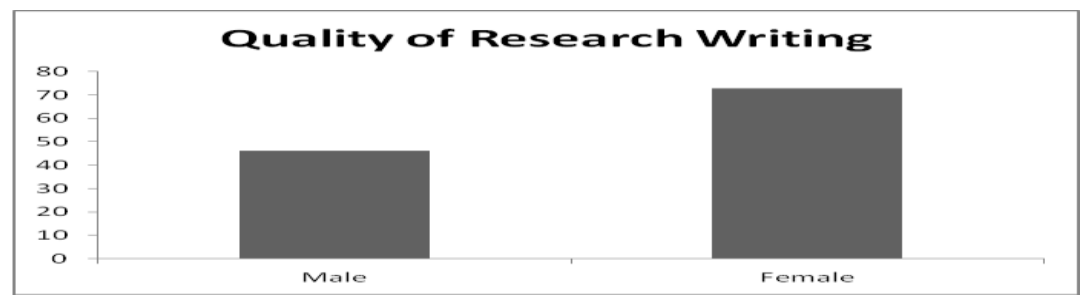

Fig.6: Main effect of gender type by quality of scientific paper writing

\section{Answering the Third Question}

The third question of the study states: What is the effect of independent-dependent levels of cognitive style on participation in online discussion, learner's perceived social presence and Quality of Scientific research writing? This type of question is presented in three sections based on the dependent variable as follows.

Cognitive Style by Participation in Online Discussion

Cognitive Style by Amount of Participation

The Group Embedded Figure Test (GEFT) was used to assign subjects into dependent and independent cognitive style. The results of the GEFT test revealed that 25 students were assigned to the dependent cognitive style pole while the rest (27 students) placed on the independent cognitive style pole. When taken cognitive style as the independent variable with the frequency of responses and percentage of response as dependent variable, the results indicated that dependent learners produced more (532) overall response than independent learners (524) and this is shown in Table 16. 
Table 16: Frequencies and percentages of postings by cognitive style

\begin{tabular}{|c|c|c|c|}
\hline Cognitive Style & $\mathrm{N}$ & Response Frequency & Percentage of Total Responses \\
\hline Independent (ID) & 27 & 524 & $49.62 \%$ \\
\hline Dependent (D) & 25 & 532 & $50.38 \%$ \\
\hline
\end{tabular}

Table 16 indicates that the frequency of postings by the dependent students is higher than the independent student's frequencies of postings. The mean number of postings posted by student in each cognitive style is presented in Table 17.

Table 17: Means and standard deviations of discussion responses by gender type

\begin{tabular}{|c|c|c|c|}
\hline Cognitive Style & N & M & SD \\
\hline Independent & 27 & 19.41 & 1.67 \\
\hline Dependent & 25 & 21.28 & 3.21 \\
\hline
\end{tabular}

Table 17 shows that the mean number of postings by dependent students is higher than in the mean number of postings by independent students. In order to estimate whether the difference in mean scores showed also indicates a significant effect, an ANOVA was conducted, and the results of the Analysis is presented in Table 18.

Table 18: The between subject effect of cognitive style by number of postings

\begin{tabular}{|c|c|c|c|c|c|}
\hline & $\begin{array}{c}\text { Sum of } \\
\text { Squares }\end{array}$ & df & Mean Square & F & Sig. \\
\hline Between Groups & 45.518 & 1 & 45.518 & 7.122 & .010 \\
\hline Within Groups & 319.559 & 50 & 6.391 & & \\
\hline Total & 365.077 & 51 & & & \\
\hline
\end{tabular}

The results of the between subject effect as shown in Table 18 indicates that there is a main effect of cognitive style $(F=7.122 ;$ df 1,$50 ; P<0.01)$ on student's mean number of postings, with the dependent learners $(\mathrm{M}=21.28$, $\mathrm{SD}=3.21$ ) having more responses than the independent learners $(\mathrm{M}=19.41, \mathrm{SD}=1.67)$, and this is shown in Fig. 7.

\subsection{Cognitive Style by Types of Participation}

When the cognitive style of learner involved by types of participation, the results showed that male subjects produced more off-topic responses than female students 


\section{Number 74, June, 2016}

whereas females produced more substantive related on-topic responses than males, and these results are presented in Table 19.

Table 19: Number of responses and percentage of on topic and off topic codes by cognitive style

\begin{tabular}{|c|c|c|c|c|c|}
\hline $\begin{array}{c}\text { Cognitive } \\
\text { Style }\end{array}$ & $\begin{array}{c}\text { No. of On } \\
\text { Topic } \\
\text { Responses }\end{array}$ & $\begin{array}{c}\text { No. of Off } \\
\text { Topic } \\
\text { Responses }\end{array}$ & $\begin{array}{c}\text { Percentage } \\
\text { of No. of On } \\
\text { Topic } \\
\text { Responses }\end{array}$ & $\begin{array}{c}\text { Percentage of } \\
\text { No. of Off } \\
\text { Topic } \\
\text { Responses }\end{array}$ & $\mathrm{N}$ \\
\hline Independent & 260 & 264 & $49.62 \%$ & $50.38 \%$ & 27 \\
\hline Dependent & 271 & 261 & $50.94 \%$ & $49.06 \%$ & 25 \\
\hline
\end{tabular}

When inspecting Table 19, it can be seen that there was a total of 1056 codes appeared with both groups, with 524 postings being shown for the independent cognitive style discussion group but 532 appeared with the dependent cognitive style group. The independent group posted more off-topic responses than the dependent group but the reverse was true for the dependent group, with the on-topic postings being higher. In order to see the significant differences between both style groups, an ANOVA was conducted, and the results are shown in Table 20.

Table 20: The between subject effect of the on-topic/off topic responses by cognitive style groups

\begin{tabular}{|c|c|c|c|c|c|c|}
\hline \multicolumn{2}{|c|}{} & Sum of Squares & Df & Mean Square & F & Sig. \\
\hline \multirow{3}{*}{$\begin{array}{c}\text { On } \\
\text { Topic }\end{array}$} & Between & 14.646 & 1 & 14.646 & 0.505 & 0.481 \\
\cline { 2 - 7 } & Within & 1450.027 & 50 & 29.000 & & \\
\cline { 2 - 8 } & Total & 1464.673 & 51 & & & \\
\hline \multirow{3}{*}{$\begin{array}{c}\text { Off } \\
\text { Topic }\end{array}$} & Between & 9.387 & 1 & 9.387 & 0.199 & 0.657 \\
\cline { 2 - 8 } & Within & 2358.536 & 50 & 47.171 & & \\
\cline { 2 - 8 } & Total & 2367.923 & 51 & & & \\
\hline
\end{tabular}

A Post hoc comparison of Tukey test (based on an alpha of .05) revealed that with respect to the on-topic postings, the dependent learners group $(M=10.84, S D=3.636)$ scored the same as the independent learners group $(M=9.78$, $S D=6.60)$. For the off-topic responses, the same pattern of 


\section{Number 74, June, 2016}

results was shown with the dependents $(M=10.48$, $S D=6.45)$ and the independents $(M=9.63, S D=7.23)$. This finding is shown in Fig. 7.

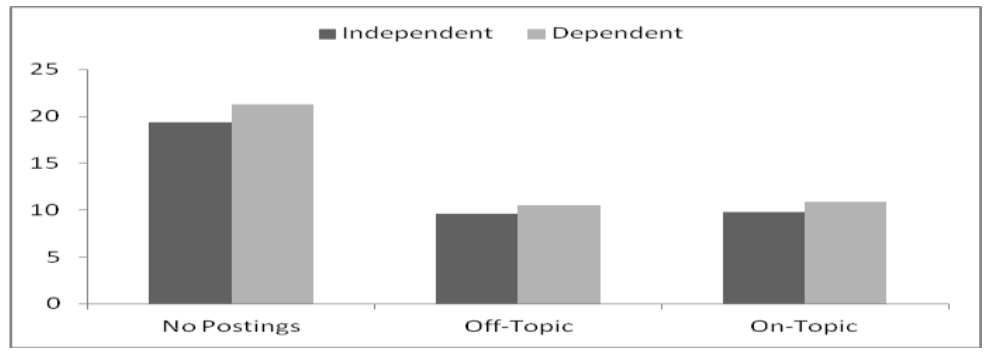

Fig.7: Main effect of cognitive style by quality of amount of postings and types of postings

\section{Cognitive Style by Perceived Social Presence}

The average mean score for the social presence scale $(\mathrm{M}=$ 3.74, $\mathrm{SD}=0.85$ ), showed that, overall, participants had high social presence in online discussions. The $95 \%$ confidence interval for this mean with dependent and independent students was 3.51 to 3.98. Therefore, overall participant social presence for both cognitive style groups would be positive.

When the analysis involved cognitive style by participant's perceived social presence, the one way ANOVA showed a main effect of the style $(F=4.15 ; d f 1$, 50; $P=0.047)$, with the dependent group $(\mathrm{M}=3.98, \mathrm{SD}=$ 0.82) having higher perceived social presence than the independent group $(\mathrm{M}=3.52, \mathrm{SD}=0.83)$, and this is shown in Table 20 and Fig. 21.

Table 21: The between subject effect of the perceived social presence by cognitive style

\begin{tabular}{|c|c|c|c|c|c|}
\hline & Sum of Squares & Df & Mean Square & F & Sig. \\
\hline Between Groups & 2.793 & 1 & 2.793 & 4.146 & .047 \\
\hline Within Groups & 33.685 & 50 & .674 & & \\
\hline Total & 36.478 & 51 & & & \\
\hline
\end{tabular}




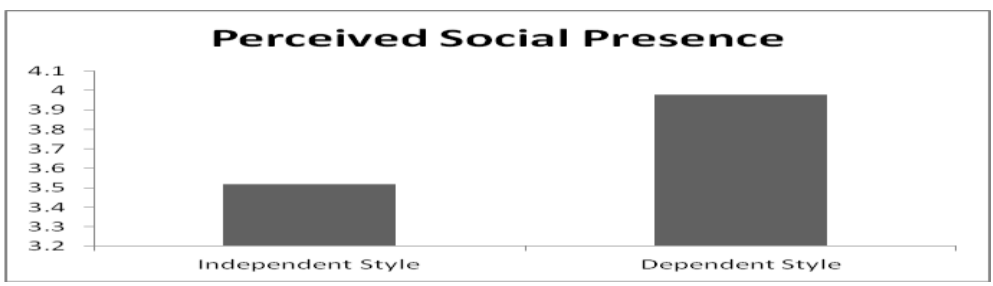

Fig.8: Main effect of cognitive style by perceived social presence

\section{Cognitive Style by Quality of Scientific Paper Writing}

When the analysis involved cognitive style by participant's scientific paper writing, the one way ANOVA showed no main effect of the style $(F=2.434 ; d f 1,50$; $P=0.125)$, with the dependent learner group $(\mathrm{M}=55$, $\mathrm{SD}=16.60)$ performed equally the same as the independent learner group $(\mathrm{M}=62.52, \mathrm{SD}=18.04)$, and this is shown in Table 22.

Table 22: The between subject effect of quality of scientific paper writing by cognitive style

\begin{tabular}{|c|c|c|c|c|c|}
\hline & Sum of Squares & df & Mean Square & F & Sig. \\
\hline Between Groups & 733.778 & 1 & 733.778 & 2.434 & .125 \\
\hline Within Groups & 15074.741 & 50 & 301.495 & & \\
\hline Total & 15808.519 & 51 & & & \\
\hline
\end{tabular}

\section{Answering the Fourth Question}

The fourth question of the study states: What are the interactions (if exist) among instructor presence, gender and cognitive style on participation, social presence and quality of scientific research writing? This type of question is presented in five sections based on the dependent variable as follows.

Interaction of Instructor Intervention by Gender by Cognitive Style by Amount of Participation (Off-topic Responses)

When the analysis of variance involved instructor intervention (instructor vs. no instructor), gender (male vs. female), cognitive style (dependent vs. independent), with the amount of participation as the dependent variable, the analysis showed that there were two interactions of gender 
by instructor intervention, $(F=11.87 ; d f 1,44 ; P=0.001$; $\eta 2=0.212$ - Fig.9), and of gender by cognitive style, $(F=$ 32.40; $d f$ 1, 44; $P=0.00 ; \eta 2=0.424$ - Fig. 10), but no interaction of style by instructor intervention, $(F=2.020 ; d f$ 1 , 44; $P=0.162 ; \eta 2=0.044)$, and no interaction of style by instructor intervention by gender, $(F=0.009 ; d f 1,44 ; P=0$. $0.92 ; \eta 2=0.000)$.

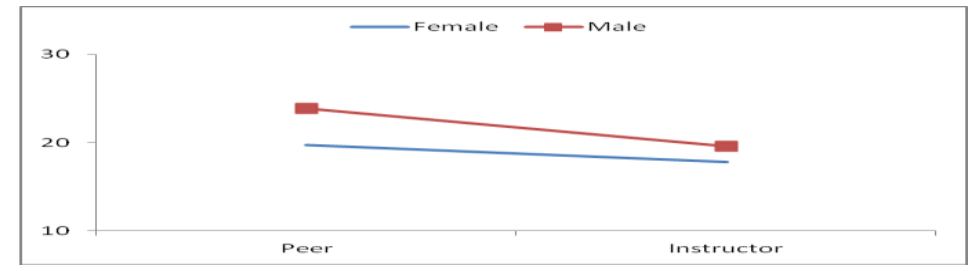

Fig.9: Interaction of instructor-peer by gender type by amount of participation

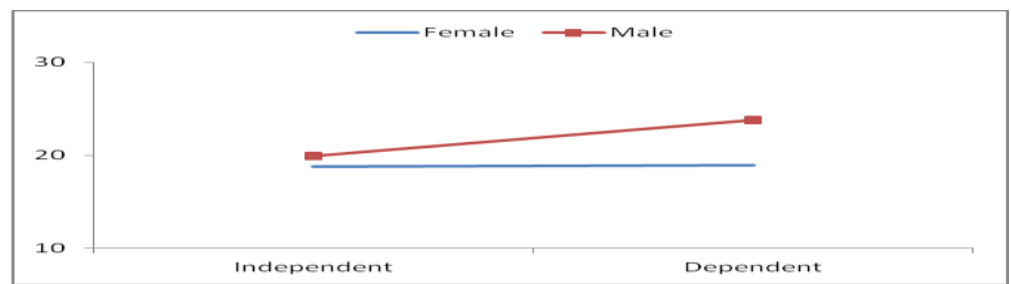

Fig.10: Interaction of cognitive style by gender type by amount of participation

Interaction of Instructor Intervention by Gender by Cognitive Style by Type of Participation

When the analysis of variance involved instructor intervention (instructor vs. no instructor), gender (male vs. female), cognitive style (dependent vs. independent), with the amount of unrelated off-topic participation as the dependent variable, the analysis showed that there were four interactions of gender by instructor intervention, $(F=20.19$; df 1,$44 ; P=0.000 ; \eta 2=0.315)$, gender by cognitive style, $(F=18.60 ; d f 1,44 ; P=0.00 ; \eta 2=0.297)$, style by instructor 
intervention, $(F=10.92 ; d f 1,44 ; P=0.002 ; \eta 2=0.199)$, and of style by instructor intervention by gender, $(F=6.405$; $d f$ 1, 44; $P=0.0 .015 ; \eta 2=0.127)$. The last interaction is presented in Fig. 11.

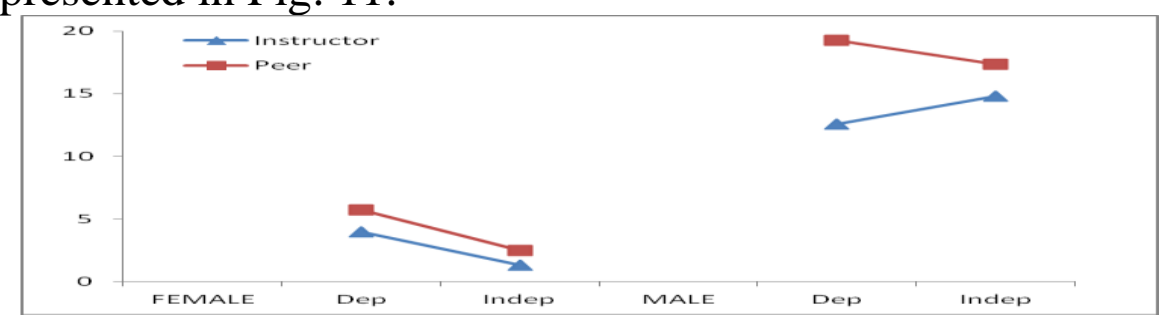

Fig.11: Interaction of instructor intervention by cognitive style by gender type by off-topic responses participation

When the analysis of variance involved instructor intervention (instructor vs. no instructor), gender (male vs. female), cognitive style (dependent vs. independent), with the amount of related on-topic participation as the dependent variable, the analysis showed that there were three interactions of gender by cognitive style, $(F=70.01$; df $1, \quad 44 ; \quad P=0.00 ; \eta 2=0.614)$, style by instructor intervention, $(F=6.405 ; d f 1,44 ; P=0.032 ; \eta 2=0.100)$, and of style by instructor intervention by gender, $(F=6.717$; $d f$ 1, 44; $P=0.0 .013 ; \eta 2=0.132-$ Fig. 12 ). The findings also showed no interaction of gender by instructor intervention, $(F=3.427 ; d f 1,44 ; P=0.071 ; \eta 2=0.072)$.

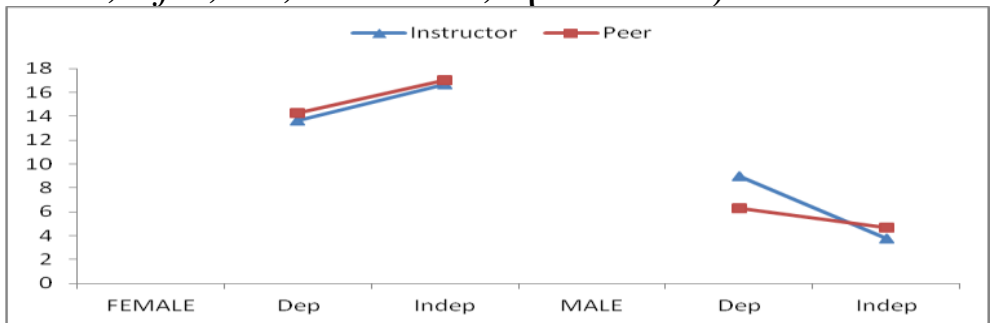

Fig.12: Interaction of instructor intervention by cognitive style by gender type by on-topic responses participation 
Interaction of Instructor Intervention by Gender by Cognitive Style by Perceived Social Presence

When the analysis of variance involved instructor intervention (instructor vs. no instructor), gender (male vs. female), cognitive style (dependent vs. independent), with the perceived social presence as the dependent variable, the analysis showed that there were two interactions of gender by instructor intervention, $(F=41.770 ; d f 1,44 ; P=0.00$; $\eta 2=0.487)$, and of style by instructor intervention by gender, $(F=4.657$; $d f 1,44 ; P=0$. $0.036 ; \eta 2=0.096$ Fig.13). The findings also showed no interaction of gender by cognitive style, $(F=0.011 ; d f 1,44 ; P=0.059 ; \eta 2=$ $0.079)$, and of style by instructor intervention, $(F=6.405 ; d f$ 1, 44; $P=0.918 ; \eta 2=0.000)$.

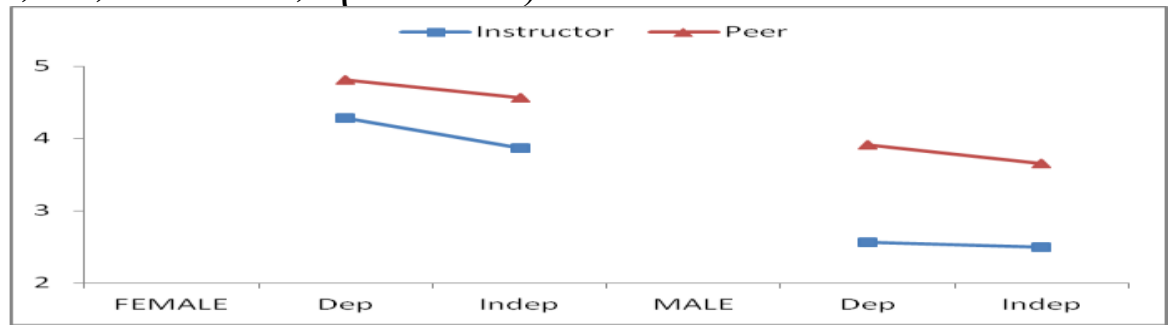

Fig.13: Interaction of instructor intervention by cognitive style by gender type by perceived social presence

Interaction of Instructor Intervention by Gender by Cognitive Style by Quality of Scientific Paper Writing

When the analysis of variance involved instructor intervention (instructor vs. no instructor), gender (male vs. female), cognitive style (dependent vs. independent), with the quality of scientific paper writing as the dependent variable, the analysis showed that there was an interaction of gender by instructor intervention, $(F=3.839$; $d f 1,44$; $P=0.05 ; \eta 2=0.080$; Fig. 14), but no interaction of gender by cognitive style, $(F=2.78 ; d f 1,44 ; P=0.0 .102 ; \eta 2=$ $0.060)$, and of style by instructor intervention, $(F=1.31 ; d f$ $1,44 ; P=0.0 .26 ; \eta 2=0.029)$, and of gender by style by 
instructor intervention by gender, $(F=0.901 ; d f 1,44$; $P=0.3478 ; \eta 2=0.020)$.

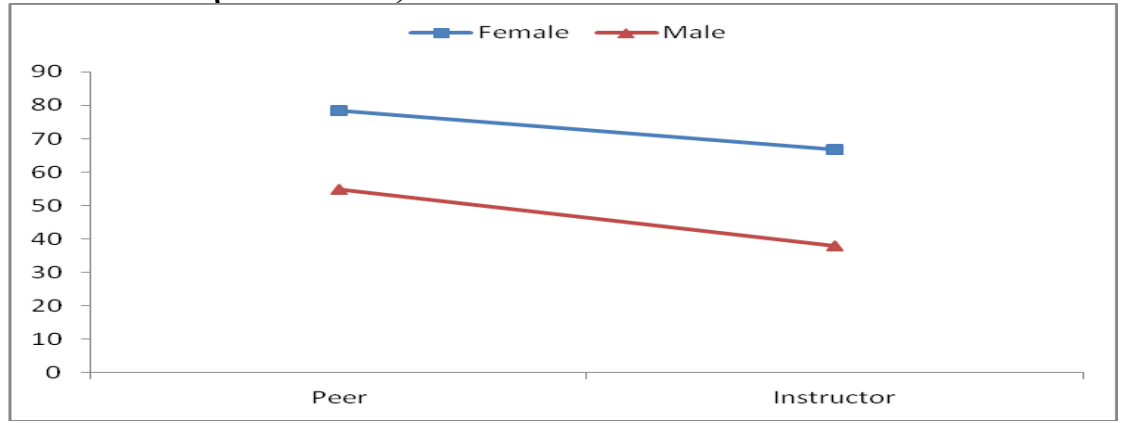

Fig.14: Interaction of instructor intervention by gender type by quality of scientific paper writing

\section{DISCUSSION}

Most instructors seek ways to enhance student discussion and student participation and foster deep learning. This study sought to extend this notion to the online environment by determining whether the presence of instructor in the online discussion impacted student participation, and whether individual differences in terms of gender and cognitive style had an effect on participation. Other questions related to perceived social presence and students' skills of writing a scientific paper were investigated.

\section{Participation in Online Discussion}

\section{Instructor Intervention and Participation}

The main question of the present study was whether students enrolled in a scientific research method course would submit a higher quality and a higher number on online discussion posts when provided with feedback or instructor postings as compared to students who received no instructor postings and feedback. Hypothesis one predicted that there would be no significant difference in the amount and type of postings between the instructor intervention group and the no instructor intervention group. Previous studies indicate that presence of instructor in online

\section{1}


discussion may hinder or increase student participation and this will depend on levels of instructor interventions (Andresen, 2009; Brookfield \& Preskill, 2012; Bedi, 2008; Guldberg \& Pikington, 2007; Mazzolini \& Maddison, 2003; Swan \& Shih, 2005).

Not all researchers agree that an instructor should facilitate the online discussion. Mazzolini and Maddison (2003), for example, found that involvement by instructors did not lead to more student postings on average. Also, instructors who were active in starting up discussion threads on average ended up with shorter discussion threads than did instructors who largely let it to the students to initiate discussions. This was echoed by Fauske and Wade (20032004) who found that students preferred not having the instructor involved in the online discussion. Students felt that the instructor's involvement could be inherently oppressive to certain students and ideas. Because of this, some researchers (e.g., Poole, 2000) have suggested the possibility that students should facilitate their own discussions.

Student-facilitation can be seen as different from instructor-facilitation. Student-facilitation is based on lateral or peer relationships while instructor-facilitation is typically seen as a hierarchical relationship (e.g., expert-novice). Because of this expert-novice relationship, an instructor's postings can prevent students from posting messages as students tend to think that the instructor's note must be the final authoritative one (Zhao \& McDougall, 2005). Further, Mazzolini and Maddison (2003) noted that some instructorfacilitation techniques, such as instructor questioning, may be more likely seen by students as an assessment tool. Hence, students may be more hesitate in responding to them.

With respect to the amount of student postings, the present study revealed that students who received no instructor intervention submitted a higher number of posts

\section{2}

Journal of Arabic Studies in Education \& Psychology (ASEP) 
than those who received intervention by the instructor. This may mean that instructor intervention hindered student postings, and therefore, the results fail to support the previous research findings that instructor participation enhance or increase the amount of student postings (Bedi, 2008; Brookfield \& Preskill, 2012). The present results are in support for the idea that instructor presence in online discussion can possibly hinder and decrease student involvement or the presence of instructor could potentially inhibit the amount of participation (Andresen, 2009; Mazzoilni \& Maddison, 2003; Swan \& Shih, 2005). Taken from the results of the study, students who had no instructor in the online discussion posted approximately (53.8\%) whereas those who had an instructor intervention posted $(46.2 \%)$ of the total postings. Further, the mean scores of postings per student was higher in the peer treatment condition $(\mathrm{M}=21.85)$ than the mean scores for the instructor intervention condition $(\mathrm{M}=18.73)$.

With respect to the type of postings (Quality of Posts), previous research suggests that instructor should provide moderate feedback to ensure some sort of quality in student postings (Guldberg \& Pilkington, 2007). In the present study, students in the instructor presence condition received at least 6-8 comments and postings from the instructor per week as a moderate feedback to ensure that student participation are on the track and prevent them from deviating from the main topic of the discussion. In spite of this moderate level of intervention, the results of the study indicated that students who received instructor intervention and those who received no instructor intervention produced equally on-topic and off-topic responses regardless of the treatment condition; therefore, the presence or absence of instructor did not contribute to student quality of postings. The findings in this section do not support the idea that

\section{3}


instructor presence in online discussions can enhance the quality of student participation (Bedi, 2008; Brookfield \& Preskill, 2012; Mandemach, Dailey-Herbert, \& DonnelliSallee, 2007). In other way, the results in this section may support the idea that instructor intervention in online discussion was found to have a fair effect on the types of student participation. Further, the results give no support for the idea that instructor intervention may hinder the quality of student participation because students in the instructor intervention condition produced the same quality of ontopic responses as the no instructor intervention condition. For the off-topic responses, both treatment groups posted approximately the same. Based on these findings, hypothesis one is not supported.

When considering participation as a whole with respect to amount and type of postings, the findings revealed that the no instructor treatment group posted more responses than the instructor presence treatment group while the quality of postings were the same for both groups. This may mean that the number or frequency of postings is not an indication of participation quality. Rather, the number and frequency of postings may indicate that students in the online discussion may approach the discussion with different styles and strategies regardless of the presence or absence of instructor postings. Another important consideration may have accounted for the results is the measurement used in the present study. Using number and frequency of postings as a measurement of amount of postings probably makes it more difficult to study in depth the participation. When considering the reasons behind the differences in posting frequency between instructor intervention and no instructor groups, one may postulate that the difference could be that the instructor-student role in traditional classroom learning impacted the amount of student postings. Because the

\section{4}


sample of the study, Saudi students, may be accustomed with a lecture based discussion environment and they may be comfortable with a passive role when it comes to participation in online discussion. In the same vine, Andresen (2009) states that increased instructor interaction in online discussion decreased learner-to-learner interaction because learners may rely on the instructor to carry the discussion; on the contrary, when the instructor is absence, possibly the learner-to-learner interaction increased because students may have taken the responsibility of their participation.

\section{Gender Type by Participation}

The second main question of the present study was whether male subjects would submit a higher quality and a higher number of postings than female subjects on online discussion regardless of the intervention of the instructor or no instructor intervention. Hypothesis two predicted that there would be no significant difference in the amount and type of postings between male and female subjects. This question is an important one and related to the previous question of instructor intervention. Previous results in the above section demonstrate that intervention or no intervention did not contribute to students' quality of postings whereas the intervention had a negative effect of the frequency and number of posts. This previous result raised another question of the increase in number of postings revealed between the two treatment groups may have been due to other factors because the differences were not shown in the quality and type of postings. One of the factors that may contribute to differences in quality and quantity of student participation could be the gender type.

Whether gender plays a role in learning behaviors has been researched in both face-to-face and online learning environments. Gender differences have been identified in traditional classroom behaviors (Crombie et al., 2003),

\section{5}




\section{Number 74, June, 2016}

showing females speak less frequently and less confidently than males (Caspi, Chajut, \& Saporta, 2008). As online learning becomes pervasive, researchers have examined the impact of gender on online learning behaviors and experiences, but the findings have been inconclusive. A number of studies found that females participated more than males, and had higher levels of satisfaction in online learning environments. For example, females read and posted more messages on the course bulletin board (e.g., Bostock \& Lizhi, 2005; Caspi et al., 2008; Gunn, McSporran, Macleod, \& French, 2003). Compared to males, females established a stronger sense of community, and perceived more learning in an online learning environment (Rovai \& Baker, 2005). In addition, more females preferred online discussion to face-to-face discussion (Bostock \& Lizhi, 2005). Females were also found to value connection and interaction, which led to their preference of learning through connectedness and a cooperative communication style (Guiller \& Durndell, 2007). On the other hand, males preferred environments allowing for more independent learning and an argumentative communication style (Guiller \& Durndell, 2007).

The results of the present study revealed that males posted more messages in the online discussion forums than females, but the quality of males' postings did not reflect superiority of males in quantity of postings. Rather, the females posted more on-topic related responses than did male counterparts. The present study indicated that with respect to amount of postings, males posted higher number of posts than female. For types of postings, males posted more off-topic unrelated responses than did female subjects whereas female participants performed better than male participants in on-topic related topics. The results in this section are not in support for the second hypothesis. Direct results in this section may not support previous results (e.g., Bostock \& Lizhi, 2005; Caspi et al., 2008; Gunn, 
McSporran, Macleod, \& French, 2003). However, these findings may be explained in terms of Biological, social, and information processing model of learning.

With respect to biological view, many differences in performance are a result of lateralization. According to the model, men were seen to use their right hemisphere brain more than females, while females tended to use more of their left hemisphere brain than males (Hamilton, 1985). If the biological explanation was true, one would refer the difference in participation in online discussion to the view that females should excel in a verbal debate dominated the discussion because females are right hemisphere which contribute to their superiority in online discussion. However, the superiority of females in the present study was only confined to the on-topic postings and not the amount and frequency of postings and this may need further investigation.

With respect to the social and environmental explanation, social learning theory focused on the surrounding environment and the effect of social community on learner's behaviors. Peers as a social agent may have an impact on learner manner and behavior. The social behavior theory suggests that males and females think and behave differently due to the alternative roles they play in society. These differences are moderated by the individual's level of gender and direct interaction with relevant social agents. For example, parents as social agent gave males more freedom to travel, interact and inspect than they gave female particularly in Saudi Arabian society. This restriction on females made them less socially connected. This may give males superiority over females in social environment. However, with the online discussion environment employed in the present study, the discussion was a single-sex discussion, so the superiority effect was probably not

\section{7}


working. This environment probably was supportive for females to engage in more meaningful participation and may have resulted in their superiority in producing more ontopic responses.

With respect to the information processing theory, the way males and females process information was viewed as a main source of gender differences in performance in many tasks. Gender was seen according to the selectivity model of information processing advanced by Meyers-Levy (1989) as having different strategies in processing a task. Men are seen as selective processors who often do not engage in comprehensive processing of all available information before giving a response. Instead, they seem to rely on various heuristics in place of detailed message elaboration (Darley \& Smith, 1995). Based on this view, participation of males in online discussion may have been based on a selective strategy (select subsets of all available information). This selective strategy may have resulted in more responses but less substantive ones because they might not have got all the contributions of others about the topic of discussion. Females, on the other hand, are considered as comprehensive processors who attempt to assimilate all available information before giving a final response. Females, according to the model, usually attempt effortful elaboration of all the available information unless they are restricted by memory constrains such as time pressure. In the present study, all students were asked to give at least two responses to comment on their peers' ideas beside their contribution in the discussion within a week period. This period of time was enough to think, rethink again, evaluate, and elaborate on the other ideas. The superiority of females over males, therefore, may have been because they are deep processors and were able to elaborate on the discussion topic and questions and so their 
contributions were more on-topic discussion than male counterparts.

\section{Cognitive Style by Participation}

One of the individual characteristics that significantly influence how students perceive online environments and participation is the cognitive style that each student employs. Cognitive styles can be described as "the way in which learners perceive, process, store, and recall attempts of learning" (James \& Gardner, 1995). Research on cognitive styles provides insight for increasing academic achievement, content design, and teaching strategies. Many researchers called for more empirical studies that include the cognitive style as a factor in online discussions (e.g. Richardson \& Newby, 2006; Wu \& Hiltz, 2004). The construct of dependent and independent cognitive style developed by Witkin and his colleagues suggests that dependent learners rely more on external environment while independent learners may depend on internal frame of organization. This may mean that dependents are more socially oriented while independents are self-oriented. This characteristic may affect learners' participation in online discussion. The present study was designed to investigate the third hypothesis which predicted that there would be no significant difference in the amount and type of postings with respect to dependent and independent cognitive style.

The results of the present study indicated that dependent learners posted more responses than independent learners did. One possible reason for this result is that dependent learners with their tendency to interact because they are more socially oriented probably posted more comments. With respect to the type participation in terms of on-andoff-topic responses, the results showed no differences between dependent and independent learners. The same pattern of results was obtained in off-topic and on-topic

\section{9}


responses. This may mean that quality of participation in online discussion is not affected by cognitive style alone, but the effect may be shown when cognitive style interacted with other variables such as instructor intervention and gender. Hypothesis three is not supported.

\section{Instructor Intervention by Gender by Style by Participation}

With respect to amount of participation, it seems that males posted more than female but the difference was clear when the instructor was absent. This may mean that instructor intervention may hinder male participation but instructor intervention did not affect female amount of participation. When cognitive style and gender are involved, participation was found to increase with dependent male subjects. It seems that females are not affected by instructor intervention and style. Males, on the other hand, are affected more by style and intervention of instructor and this effect contributes to their online discussion participation; this latest result needs more research.

With respect to type of participation, for off-topic responses, the results showed that there was an interaction of gender by instructor intervention, with males showing higher off-topic unrelated responses when they were dependents. These off-topic responses showed an increase when dependent males were interacted without the presence of instructor (peer feedback condition), but when the instructor was present, off-topic responses dropped. One possible reason for this effect is that males seem to use a selective strategy when processing information, this strategy may cause many mistakes and superficial processing of information, the results then were more chatting and unrelated responses. On the other hand, females showed lower level of off-topic unrelated posts than male subjects; probably because they are deep processor of information and take their time in thinking before give a response. When

\section{0}


we look at the on-topic response, the results showed that females produced more substantive responses than males did regardless of style and instructor intervention whereas for male subjects producing on-topic responses were affected more by structure of the online discussion. When the instructor was present in the discussion, males' posts were higher and related particularly when they are dependent learners. It seems that males need more help from the instructor to adjust their participation, when the instructor is absent; more off-topic responses are expected.

\section{Learner perceived Social Presence}

\section{Instructor Intervention by Social Presence}

Learner perceived Social presence was measured in the present study based on a 30 item-four section questionnaire. The questionnaire measured in its first section how the learners perceived the mutual attention and support given to them during the online discussion. The second section estimated to what extent the learners feel affective connectedness. The third section measured sense of community in the learner. The fourth dimension of the scale estimated the learners' view or opinion about open communication. Based on the results of the present study, social presence of learner was overall higher, meaning that all postgraduate students in the study having positive social presence. In terms of instructor intervention effect, it was hypothesized that presence of instructor or absence would not affect learner perceived social presence. The results of the study indicated that social presence of learner was affected by instructor intervention, with the no instructor intervention group (peer feedback) showing higher perceived social presence than those in the instructor intervention group. The results may mean that instructor presence in the online discussion inhibited the feelings of social presence in the learners. This result may support the previous results of the present study in the participation

\section{1}


section particularly the findings in the amount of participation. Amount of participation was found to be higher in the peer feedback condition (no instructor intervention) than in the instructor intervention condition. Social presence as defined in the literature may mean that the ability of learners to project themselves socially and emotionally as real people in the online discussion. It seems that presence of an instructor in the discussion inhabited this ability and decreased learners' feelings to open communicate with others, decreased also their feelings to belonging to a group, decreased a sense of community among participations, and lower the affective connectedness feelings. In this line, online discussion needs learners to be socially connected and this can happen by encouraging more peer feedback and less instructor feedback.

\section{Gender Type by Social Presence}

With respect to gender by perception of social presence, hypothesis five predicted that learner's perceived social presence would not be affected by gender type. The results of the present study indicated that female participants showed higher perception of social presence than males did. Also, when involved gender by instructor intervention, both genders had higher perceived social presence with the no instructor intervention condition (peer condition). Studies suggest that females and males may differ in how they interact, how much they interact, and how connected they are in the e-learning environment. For example, Gender Role Theory (Eagly, 1987) suggests that females are more attuned to the socially oriented aspects of communication. In addition, they are more concerned with creating and maintaining relationships and familiarity in those relationships (Tannen, 1990; Wood \& Rhodes, 1992). Finally, females are more likely to use communication to develop and maintain connections and community (Tennen, 1990).

\section{2}


Based on the above view and suggestion, one could predict that this tendency of females to be network focused in their communication can lead to increase interaction and stronger perception of peer presence. For example, the tendency of females to emphasize social interaction in communication may lead to greater online discussion interaction in the course as they seek to develop relationships with peers and instructors. They may take fuller advantage of the collaborative nature of the discussion tool. Second, females have been found to use technology for the development and maintenance of social relationships (Boneva, Kraut, \& Frohlich, 2001). Thus, it could be believed that females' communication patterns should also be socially oriented, with the goal of developing a shared and more intimate learning context. This in turn should lead to females having greater perceptions of social presence than males. Based on the above results, hypothesis five is not supported.

\section{Cognitive Style by Social Presence}

Hypothesis six of the present study predicted that there would be no significant difference between dependent and independent learners in perceived social presence. The results of the present study showed that dependent learners had higher perception of social presence than independent learners. Therefore, hypothesis six is not supported. Cognitive style refers to a psychological dimension that represents consistencies in the way in which individuals process and acquire information (Ausburn \& Ausburn, 1978). Messick (1984) defines cognitive style as "consistent individual differences in preferred ways of organizing and processing information and experience" (p. 5). Fieldindependent learners are characterized as operating within an internal frame of reference, intrinsically motivated with self-directed goals, structuring their own learning, and

\section{3}


defining their own study strategies. Field dependent learners on the other hand are characterized as relying more on an external frame of reference, are externally motivated, respond better to clearly defined performance goals, have a need for structuring and guidance from the instructor, and desire to interact with other learners (Cassidy, 2004).

It seems that dependent learners, because of their reliance on external frame of reference in the online discussion, their perceived social presence were affected. That is, feeling of mutual attention and support from other peers in the environment may have increased their perception of socially connected. Further, affective connectedness, sense of community and open communication were all related to how good the dependent learners were interacted with their peers and instructor. Peers and instructor were external agents who were constituted the dependent and independent learners' assistance. Because dependent learners are more reliant on external agents, leading them to interact more, this may have resulted in their feelings of satisfaction and socially presence.

\section{Learner's Quality of Scientific Paper Writing}

Hypotheses from seven to nine predicted that there would be no significant difference in quality of writing a research paper with respect to instructor intervention, gender type, and cognitive style respectively. When the quality of scientific paper writing was analyzed, two important findings were shown; one was the effect of instructor intervention and the second was the effect of gender. The same pattern of results shown in participation and social presence was also shown with quality of leaner's writing, with the no instructor intervention and females being better on quality of writing rubric. Based on these two results related to instructor intervention and gender type, hypothesis seven and eight are not supported. This may

\section{4}


mean that doing better on writing a scientific research paper was probably associated with the quality of participation and gender feelings of socially presence. In the same vine, presence of instructor and male participants did worse than females on measurements of participation quality (type of participation), social presence and quality of writing a research paper. With respect to cognitive style, the results of the present study indicated that independent learners were better in writing than dependent learners. In terms of cognitive style, it seems that the characteristic of the independent learners were the causes for this result as they are internally guided and pose their structure upon the material, this may have leaded them to perform better on the writing tasks. Further, studied suggests that independent learners are excelling in writing tasks, and the present results may support this finding. The results in type of participation and social presence sections are different from the results in the quality of writing section, in that, quality of student participation was not affected by style and the dependent learners had higher social presence. These discrepancies of results need further investigation. Based on the results in the cognitive style, hypothesis nine is not supported.

\section{IMPLICATIONS \& FUTURE DIRECTIONS}

The present study found that instructor intervention in the online discussion had a negative effect on the amount of postgraduate postings, but with the type of postings, presence or absence of instructor was found to have no effect. The results, overall, do not support the idea that instructor intervention in the online discussion may enhance the quality and quantity of learners' participation. Based on these findings, instructional designers of online courses should not base their structure of online discussion on the idea that participation in terms of quality and quantity of postings will increase when the instructor is presence in the

\section{5}

Journal of Arabic Studies in Education \& Psychology (ASEP) 
discussion; rather, they should be guided by the idea that learners may approach the discussion with different types of processing and strategies, and therefore, other variables related to learners' individual differences may account for the differences. Future studies should be conducted to reveal the other factors that may contribute to students' quality and quantity of participation. In the same vine, instructor interventions in the online discussion may be investigated with a varying degree of facilitations, that is, studies should focus on the type of instructor facilitations that may produce more quality and quantity of participation such as levels of interventions high, moderate and low. Further studies also should be done on the role of peers as facilitators and to reveal the underlying factors that assist in participation.

There is, however, comparatively little research done that directly addresses student-or-peer facilitation compared to instructor facilitation. It seems that asynchronous discussion facilitates student-centered instruction and provides the opportunity to construct knowledge with peers (Conrad \& Donaldson, 2012; Palloff \& Pratt, 2010). Fundamental questions remain unanswered. For example, what perceptions do students have toward facilitating their own discussion? What exactly motivates students to contribute in student-facilitated online discussions? To address these questions, future studies should consider these issues.

Another important implication of the results may be related to the traditional view of the teacher and instructor role. The results of the present study revealed that presence of instructor in online discussion hindered the quantity of postings and did not contribute to enhancing the quality of learners' postings. Probably learners in the presence of instructor had adopted a passive role the same as the role they are accustomed to in traditional learning environment and this may have hindered their contributions. If this

\section{6}


predicting was true, one could say that changing students' view of the role of teachers and instructor should be a mandatory task for instructional organizations and instructors. Further research should concentrate on investigating the learners' views of the instructors as feedback giver, facilitators, and evaluators and so on in the discussion and to what extent these roles are different in traditional and online environments.

The results in social presence showed that the no instructor intervention group had higher perceived social presence than the instructor intervention group. It seems that the results in the social presence section are mainly connected with the results in participation section and both participation and social presence are related, and this needs further investigation.

One important consideration may contribute for the results of the present study are the measurement used in counting the number of postings as measure of amount of postings. This measure probably makes it difficult to study participation in depth. Using number of posts did not reflect a good measure of amount of participation. Further research may employ different styles of measurements in estimating the amount of postings such as length of postings and other types of measures.

With respect to gender type, the results also in participation and social presence sections showed a similar pattern, with the female participants scoring better than male participants. Males and females probably have different strategies in working generally in online environment and particularly online discussions. Another potential topic for future research would be an attempt to investigate more the effect of the gender type with different facilitation techniques such as a variety of peer facilitation

\section{7}


in online discussion. Still another future topic to be discussed would be the factors that leaded male subjects to post more responses in peer facilitation condition but when instructor presence their responses dropped and why male subjects produced more on-topic responses when the instructor intervened in the discussion. One important future consideration would be to study the reasons behind superiority of females on producing on-topic related responses whereas males on producing more off-topic responses. Does the selectivity model of information processing of males and females work here in the online discussion?

With respect to cognitive style, numbers of postings were higher with the dependent learners than with the independent learners in the present study. But for the on and off-topic responses, there were no differences. With social presence, the dependents had higher perception of social presence. With respect to writing skills, the independents showed superiority over the dependents. The results may indicate the tendency of the dependent learners to be more socially connected and this may have resulted in their higher participation number. But for the skills in writing a research, the results may indicate that this ability and skill may need depth in processing which is probably a characteristic of the independents. Overall, cognitive style factor in online discussion participation may need further research.

\section{CONCLUSION}

To conclude, the present study was designed to reveal the effect of instructor intervention in the online discussion on postgraduate learners' participation, social presence and quality of research writing. Gender and cognitive style were investigated singly and interaction with the instructor interventions to reveal whether these variables had some

\section{8}


sort of effects on the results. Overall, based on the results of the study, the main conclusion is that instructor intervention in online discussions has to be implemented with some cautions since the effect may hinder learners' amount of postings and its effect with the type of participation is not clear enough. Further, gender in the present study has a powerful effect on participation so the findings in the present study should be taken into consideration when instructors, designers and developers are in position to structure online discussions as a web-enhanced tool complement traditional classroom courses. An important conclusion was the one related to social presence. Social presence seems to be highly related to participation and the present study perhaps suggests that increasing participation may lead to increase social presence. Finally, cognitive style results of the present study should be treated with cautions and need more investigations.

\section{REFERENCES}

- Abawajy, J. (2012). Analysis of asynchronous online discussion forums for collaborative learning. International Journal of Education and Learning, 1(2), 11-21.

- Abel, R. (2005). Achieving success in Internet-supported learning in higher education: Case studies illuminate success factors, challenges, and future directions. Lake Mary, FL: Alliance for Higher Education Competitiveness.

- Allinson, L. (1992) Learning styles and computer-based learning environment. In I. Tomek (Ed.), Computer assisted learning. 4th international conference, Berlin (PP. 61-73). London: SpringerVerlag.

- Al-sharkawy, A., and Al-Khoudary, S. .(2002). Group Embadded Figure Test: Instructions Booklet. 6th ed. Cairo: Al-Anglo-Almasria bookshop.

- Andresen, M. A. (2009). Asynchronous discussion forums: Success factors, outcomes, assessments, and limitations. Educational Technology \& Society, 12(1), 249-257. 


\section{Number 74, June, 2016}

- Anderson, D.M., \& Haddad, C.J. (2005). Gender, voice, and learning in online course environments, Journal of Asynchronous Learning Networks, 9(1). Available online at http://www.sloanc.org/ publications/jaln/v9n1/v9n1_anderson.asp\#anderson7.

- Arbaugh, J. B. (2000). An exploratory study of the effects of gender on student learning and class participation in an Internet-based MBA course. Management Learning, 31, 503-519.

- Arend, B. (2009). Encouraging critical thinking in online threaded discussions. The Journal of Educators Online, 6(1).

- Ausburn, L. J., \& Ausburn, F. B. (1978). Cognitive styles: some implications for instructional design. Educational Communication \& Technology Journal, 26, 337-354.

- Bali, M. \& Ramadan, A.R. (2007). Using rubrics and content analysis for evaluating online discussion: a case study from an environmental course. Journal of Asynchronous Learning Networks, 11(A), 19-33.

- Baran, E., \& Correia, A-P. (2009). Student-led facilitation strategies in online discussions. Distance Education, 30(3), 339-361.

- Barrett, E., \& Lally, V. (1999). Gender differences in an on-line learning environment. Journal of Computer Assisted Learning, 15(1), 48-60.

- Beaudoin, M. F. (2002). Learning or lurking? Tracking the "invisible" online student. The Internet and Higher Education, 5(2), 147-155.

- Bedi, K. (2008). Best practices of faculty in facilitating online asynchronous discussions for higher student satisfaction. U21Global Working Paper Series, No. 005/2008. doi:10.2139/ssrn.1601047

- Bender, T. (2003). Discussion based online teaching to enhance student learning: Theory, practice and assessment. Sterling, VA: Stylus.

- Biggs, J. (1987). Student approaches to learning and studying. Hawthorn, Victoria: Australian Council for Educational Research.

- Boneva, B., Kraut, R., \& Frohlich, D. (2001). Using e-mail for personal relationships. The American Behavioral Scientist, 45(3), 530-549. 


\section{Number 74, June, 2016}

- Bostock, S. J., \& Lizhi, W. (2005). Gender in student online discussions. Innovations in Education and Teaching International, 42(1), 73-85.

- Brookfield, S. D., \& Preskill, S. (2012). Discussion as a way of teaching: Tools and techniques for democratic classrooms (2nd ed.). San Francisco, CA: Jossey-Bass.

- Canada, K., \& Pringle, R. (1995). The role of gender in college classroom interactions: a social context approach. Sociology of Education, 68, 161-186.

- Canter, L. L. S., Voytecki, K. S., \& Rodriguez, D. (2007). Increasing online interaction in rural special education teacher preparation programs. Rural Special Education Quarterly, 26(1), 23-27.

- Carrier, C.A., Davidson, G., Higson, V., \& Williams, M. (1984). Selection of options by field-independent and dependent children in a computer-based concept lesson. Journal of Computer-Based Instruction, 77(2), 49-54.

- Caspi, A., \& Blau, I. (2008) Social presence in online discussion groups: testing three conceptions and their relations to perceived learning. Social Psychology Education, 11, 323-346.

- Caspi, A., Chajut, E., Saporta, K., \& Beyth-Marom, R. (2006). The influence of personality on social participation in learning environments. Learning and Individual Differences, 16(2), 129-144.

- Caspi, A., Chajut, E., \& Saporta, K. (2008). Participation in class and in online discussions: Gender differences. Computers \& Education, 50(3), 718-724.

- Cassidy, S. (2004). Learning styles: an overview of theories, models, and measures. Educational Psychology, 24, 419-444.

- Chen, N. S., Kinshuk, Wei, C. W., \& Yang, S. J. H. (2008). Designing a self-contained group area network for ubiquitous learning. Educational Technology and Society, 11(2), 16-26.

- Cheung, W. S., \& Hew, K. F. (2004). Evaluating the extent of illstructured problem solving process among pre-service teachers in an asynchronous online discussion and reflection log environment. Journal of Educational Computing Research, 30(3), 197-227.

- Cheung, W. S., \& Hew, K. F. (2010). Examining facilitators' habits of mind in an asynchronous online discussion environment: A two cases study. Australasian Journal of Educational Technology, 26(1), 123-132. 


\section{Number 74, June, 2016}

- Coates, J. (1993). Women men and language (2nd ed.). New York: Longman Inc.

- Coetzee D., Fox, A., Hearst, M.A., \& Hartmann, B. (2014). Should your MOOC forum use a reputation system. In Proc. conference on Computer supported cooperative work \& social computing, (pp. 1176-1187). ACM Press.

- Conrad, R. M., \& Donaldson, J. A. (2011). Engaging the online learner: Activities and resources for creative instruction. San Francisco, CA: Jossey-Bass.

- Coomey M and Stephenson, J (2001) Online Learning: it is all about dialogue, involvement, support and control-according to the research, in Teaching and Learning Online: Pedagogies for New Technologies, ed. J. Stephenson, Kogan Page, London, UK

- Crombie, G., Pyke, S. W., Silverthorn, N., Jones, A., \& Piccinin, S. (2003). Students' perception of their classroom participation and instructor as a function of gender and context. Journal of Higher Education, 74(1), 51-76.

- Correia, A. P., \& Baran, E. (2010). Lessons learned on facilitating asynchronous discussions for online learning. Educacao, Formacao \& Tecnologias, 3(1), 59-67.

- Darley, W. K., and Smith, R. E. (1995) Gender differences in information processing strategies: an empirical test of the selectivity model in advertising response. Journal of Advertising, 24(1), 41-56.

- Davidson-Shivers, G. V., Ellis, H. H., \& Amarasing, K. (2005). How do female students perform in online debates and discussion? In G. Richards (Ed.), Proceedings of World Conference on E-Learning in Corporate, Government, Healthcare, and Higher Education 2005 (pp. 1972-1977). Chesapeake, VA: AACE.

- Davidson-Shivers, G. V., Morris, S., \& Sriwongkol, T. (2003). Gender differences: Are they diminished in on-line discussions? International Journal on E-Learning, 2(1), 29-36.

- Davidson-Shivers, G. V., Muilenburg, L., \& Tanner, E. (2001). How do students participate in synchronous and asynchronous on-line discussions? Journal of Educational Computing Research, 25, 351366.

- Davidson-Shivers, G. V., Muilenburg, L., \& Tanner, E. (2000, June). Synchronous and asynchronous discussion: What are the differences in student participation? Ed-Media 2000: World Conference on 


\section{Number 74, June, 2016}

Educational Multimedia, Hypermedia \& Telecommunications. Montreal, Quebec, Canada.

- Dee, T. (2006). The why chromosome: How a teacher's gender affects boys and girls. Education Next, 6(4), 68-76.

- Dennen, V.P. (2005). From message posting to learning dialogues: Factors affecting Learner participation in asynchronous discussion. Distance Education, 26, 127-148.

- Dennen, V. P. (2008). Looking for evidence of learning: Assessment and analysis methods for online discourse. Computers in Human Behavior, 24(2), 205-219.

- De Wever, B., Schellens, T., Valcke, M., \& Van Keer, H. (2006). Content analysis schemes to analyze transcripts of online asynchronous discussion groups: A review. Computers \& Education, 46(1), 6-28.

- Duffy, J., Warren, K., \& Walsh, M. (2001). Classroom interactions: Gender of teacher, gender of student, and classroom subject. Sex Roles, 45, 579-593.

- Eagly, A. H. (2987). Sex differences in social behavior: a social role interpretation. NJ: Earlbaum.

- Entwistle, N. (1981) Styles of learning and teaching: an integrated outline of educational psychology for students, teachers and lecturers. Chichester: John Wiley.

- Erlich, Z., Erlich-Philip, I., \& Gal-Ezer, J. (2005). Skills required for participating in CMC courses: An empirical study. Computers \& Education, 44, 477-487.

- Ertmer, P. A., Richardson, J. C., Belland, B., Camin, D., Connolly, P., Coulthard, G., (2007). Using peer feedback to enhance the quality of student online postings: an exploratory study. Journal of Computer Mediated Communication, 12(2), 412-433.

- Farag, M A. (2016) Instructor Guidelines and Group Size as Moderating Factors Affecting Quality and Quantity of Online Discussion Participation, Satisfaction and Learning. Journal of Research in Curriculum, Instruction, and Educational Technology (JRCIET). In Press.

- Fauske, J., \& Wade, S. E. (2003-2004). Research on practice online: conditions that foster democracy, community, and critical thinking in computer based discussions. Journal of Research on Technology in Education, 36(2), 137-153. 
- Garrison, D. R., \& Anderson, T. (2003). E-learning in the 21st century: A framework for research and practice. London: Routledge Falmer.

- Garrison, D. R., Anderson, T., \& Archer, W. (2000). Critical inquiry in a text-based environment: computer conferencing in higher education. The Internet and Higher Education, 2(2-3), 87-105.

- Gaulin, S. J. C., and Hoffman, H. H. (1988) Evolution and development of sex differences in spatial ability. In L. Betzig, M. B. Mulder, \& P. Turke (Eds.), Human reproductive behaviour: a Darwinian perspective. Cambridge, Cambridge University Press (pp. 129-152).

- Gilbert, P. K., \& Dabbagh, N. (2005). How to structure online discussions for meaningful discourse: A case study. British Journal of Educational Technology, 36(1), 5-18.

- Goldstein, K. M., and Blackman, S. (1978) Cognitive style: five approaches and relevant research. NY: Wiley.

- Graddol, D., \& Swan, J. (1989). Gender voices. Cambridge, MA: Basil Blackwell.

- Grigorenko, E. L., and Sternberg, R. J. (1995) Thinking styles. In D. H. Saklofske and M. Zeidner (Eds.), Instructional handbook of Personality and intelligence (PP. 205-230). NY: Plenum Press.

- Gulati, S. (2008, May). Compulsory participation in online discussion: is this constructivism or normalization of learning? Innovation in Education and Teaching International, 45(2), 183-192.

- Guiller, J., \& Durndell, A. (2007). Students' linguistic behavior in online discussion groups: Does gender matter? Computers in Human Behavior, 23, 2240-2255.

- Guldberg, K., \& Pilkington, R. M. (2007). Tutor roles in facilitating reflection on practice through online discussion. Educational Technology \& Society, 10(1), 61-72.

- Gunawardena, C.N., \& McIssac, M.S. (2003). Distance education. In D.H. Jonassen (Ed.), Handbook of research in educational communications and technology (pp. 355-396). Mahwah, NJ: Lawrence Erlbaum Associates.

- Gunn, C., McSporran, M., Macleod, H., \& French, S. (2003). Dominant or different? Gender issues in computer supported learning. Journal of Asynchronous Learning Networks, 7(1), 14-30. 


\section{Number 74, June, 2016}

- Hall, R. M., \& Sandler, B. R. (1984). Out of the classroom: a chilly campus climate for women? Washington, DC: Project on the Status and Education of Women, Association of American Colleges.

- Hamilton, C. J. (1995) Beyond sex differences in visuo-spatial processing: the impact of gender trait possession. British Journal of Psychology, 86(1), 1-21.

- Hammond, M. (2005). A review of recent papers on online discussion in teaching and learning in higher education. Journal of Asynchronous Learning Networks, 9(3), 9-23.

- Hannafin, M. J. (1984). Guidelines for using locus of instructional control in the design of computer-based instruction. Journal o $\mathrm{f}$ Instructional Development, 7(3), 6-10.

- Heckman, R. \& Annabi, H. (2006). Cultivating voluntary online learning communities in blended environments. Journal of Asynchronous Learning Networks, 10(4), 51-66.

- Herring, S. C. (1993). Gender and democracy in computer-mediated communication. Electronic Journal of Communication [online], 3.

- Hew, K. F., \& Cheung, W. S. (2003a). An exploratory study of the use of asynchronous online discussion in hypermedia design. Journal of Instructional Science \& Technology, 6(1), 12-23.

- Hew, K. F., \& Cheung, W. S. (2003b). Evaluating the participation and quality of thinking of pre-service teachers in an asynchronous online discussion environment: Part II. International Journal of Instructional Media, 30(4), 355-366.

- Hew, K. F., Cheung, W. S., \& Ng, C. S. L. (2010). Student contribution in asynchronous online discussion: a review of the research and empirical exploration. Instructional Science, 38(6), 571-606.

- Hew, K. F., Liu, S., Martinez, R., Bonk, C., \& Lee, J. Y. (2004). Online education evaluation: what should we evaluate? The Proceedings of the Association for Educational Communications and Technology (pp. 243-246). Chicago, IL: Association for Educational Commnications and Technology.

- Hewitt, J. (2005). Toward an understanding of how threads die in asynchronous computer conferences. Journal of the Learning Sciences, 14(4), 567-589.

- Jeong, A. C , \& Davidson-Shivers, G. V. (2006). The effects of gender interaction patterns on student participation in computer- 


\section{Number 74, June, 2016}

supported collaborative argumentation. Educational Technology Research and Development, 54, 543-568.

- Jeong, A. C , \& Davidson-Shivers, G. V. (2006). The effects of gender interaction patterns on student participation in computersupported collaborative argumentation. Educational Technology Research and Development, 54, 543-568.

- Johnson, G. M., \& Buck, G. H. (2007, April). Asynchronous and synchronous online discussion: Real and perceived achievement differences. Paper presented at the annual meeting of the American Educational Research Association, Chicago, IL.

- Jonassen, D. H., and Grabowski, B. L. (1993) Handbook of individual differences: learning and instruction. Hillsdale, NJ: Lawrence Erlbaum.

- Jones, E. R. (1999). A comparison o f an all web-based class to a traditional class. Paper presented at the Society for Information Technology \& Teacher Education International Conference (10th, San Antonio, TX, February 28-March 4,1999). (ERIC Document Reproduction Service No. ED432286)

- La Pointe, K. D., \& Gunawarndena, C. (2004). Developing testing and refining of a model to understand the relationship between peer interaction and learning outcomes in computer-mediated conferencing. Distance Education, 25(1), 93-106.

- Kegan, J., Rosman, B., Day, D., Albert, J., and Philips, W. (1964) Information processing and the child: significance of analytic and reflective attitudes. Psychological Monographs, 78, 578.

- Keddie, A. (2003). Little boys: Tomorrow's macho lads. Discourse: Studies in the Cultural Politics of Education, 24(3), 289-306.

- Khine, M., Yeap, L., \& Lok, A. (2003). The quality of message ideas. Thinking and interaction in an asynchronous CMC environment. Educational Media International, 40(1-2), 115-125.

- Ko, S., Ko, S. S., \& Rossen, S. (2010). Teaching online: A practical guide (3rd ed.). New York, NY: Routledge.

- Light, V., Nesbitt, E., Light, P., \& Burns, J. R. (2000). 'Let's you and me have a little discussion': computer mediated communication in support of campus-based university courses. Studies in Higher Education, 25, 85-96.

- Mandernach, J., Dailey-Hebert, A., \& Donnelli-Sallee, E. (2007). Frequency and time investment of instructors' participation in 
threaded discussions in the online classroom. Journal of Interactive Online Learning, 6(1), 1-9.

- Marra, R. M., Moore, J. L., \& Klimczak, A. K. (2004). Content analysis of online discussion forums: A comparative analysis of protocols. Educational Technology Research and Development, 52(2), 23-40.

- Markus, M. L. (1994). Finding a happy medium: explaining the negative effects of electronic communication on social life at work. ACM Transactions on Information Systems, 12, 119-149.

- Marshall, C, \& Reinhartz, J. (1997). Gender issues in the classroom. The Clearing House, 70, 333-337.

- Masters, K., \& Oberprieler, G. (2004). Encouraging equitable online participation through curriculum articulation. Computers and Education, 42, 319-332.

- Mazzolini, M., \& Maddison, S. (2003). Sage, guide or ghost?: The effect of instructor intervention on student participation in online discussion forums. Computers and Education, 40, 237-253.

- Mazzolini, M., \& Maddison, S. (2007). When to jump in: The role of the instructor in online discussion forums. Computers \& Education, 49, 193-213.

- Meehan, S. (2005). The Pygmalion effect: A study examining the influence of teacher expectancy on student performance. Retrieved July 28, 2007 from http://www.tcnj.edu/-meehan2/Inquiry.htm

- Messick, S. (1994) The matter of style: manifestations of personality in cognition, learning and teaching. Educational Psychologists, 29(3), 121-136.

- Messick, S. (1984) The nature of cognitive style: problems and promise in educational practice. Educational Psychologist, 19(2), 5974.

- Messick, S. (1987). Structural relationships across cognition, personality, and style. Aptitude. Learning, and Instruction, 3, 35-75.

- Meyers-Levy, J. (1989) Gender differences in information processing: a selectivity interpretation. In Patricia Cafferate \& Alice Tybout (Eds.), Cognitive and affective responses to advertising. Lexington, MA: Lexington (pp. 219-260). 
- Meyers-Levy, J. (1991) Elaboration on elaboration: the distinction between relational and item-specific elaboration. Journal of Consumer Research, 18 (December), 358-367.

- Meyers-Levy, J., and Maheswaran, D. (1991) Exploring differences in males' and females' processing strategy. Journal of Consumer Research, 18 (June), 63-70.

- Meyers-Levy, J., and Strenthal, B. (1991) Gender differences in the use of message cues and judgements. Journal of Marketing Research, 28 (Feb.), 84-96.

- Miller, J., \& Durndell, A. (2004). Gender, language and computermediated communication. In K. Morgan, C. A. Brebbia, J. Sanchez, \& A. Voiskounsky (Eds.), Human perspectives in the Internet society: culture, psychology and gender (pp. 235-244). Southampton: WIT Press.

- Moore, M. G. (2002). What does research say about learners using computer-mediated communication in distance learning. The American Journal of Distance Education, 16(2), 61-64.

- Moran, A. (1991) What can learning styles research learn from cognitive psychology? Educational Psychology, 11(3-4), 339-345.

- Morgan, H. (1997). Cognitive styles and classroom learning. Westport, CT: Praeger.

- Moussa, M. A. F. (2005). Media presentation type, cognitive style, gender and recall performance. PhD, University of Birmingham, England.

- Muilenburg, L. Y., \& Berge, Z. L. (2005). Student barriers to online learning: A factor analytic study. Distance Learning, 26(1), 29-48.

- Muirhead, B. (2005). Integrating critical thinking into online classes. Insights for Teachers and Students, 82 82-85.

- Murphy, E., \& Coleman, E. (2004). Graduate students' experiences of challenges in online asynchronous discussions [Electronic Version]. Canadian Journal of Learning and Technology, 30.

- Oltman, P. K., Raskin, E., \& Witkin, H. A. (1971). Group embedded figure test. Palo Alto, CA: Consulting Psychologists Press.

- Palincsar, A. S., \& Herrenkohl, L. R. (2002). Designing collaborative learning contexts. Theory Into Pract, 41(1), 26-32.

- Palloff, R. M., \& Pratt, K. (2010). Collaborating online: Learning together in community. San Francisco: Jossey-Bass. 


\section{Number 74, June, 2016}

- Palloff, R. M., \& Pratt, K. (2003). The virtual student: A profile and guide to working with online learners. CA: Jossey-Bass.

- Palmer, S., Holt, D., \& Bray, S. (2008). Does the discussion help? The impact of a formally assessed online discussion on final student results. British Journal of Educational Technology, 39(5), 847-858.

- Pena-Shaff, J., Altman, W., \& Stephenson, H. (2005). Asynchronous online discussions as a tool for learning: Students' attitudes, expectations, and perceptions. Journal of Interactive Learning Research, 16(4), 409-430.

- Pituch, K.A., \& Lee, Y. (2006). The influence of system characteristics on e-learning use. Computers and Education, 47, 222-244.

- Poole, D. M. (2000). Student participation in a discussion-oriented online course: a case study. Journal of Research on Computing in Education, 33(2), 162-177.

- Pollock, P. H., Hamann, K., \& Wilson, B. M. (2005). Teaching and learning online: assessing the effect of gender context on active learning. Journal of Political Science Education, 1, 1-15.

- Raven, M.R., Cano, J., Garton, B.L., \& Shelhamer, V. (1993) A comparison of learning styles, teaching styles, and personality styles of preservice Montana and Ohio agriculture teachers. Journal of Agricultural Education, 31(1), 40-50.

- Richardson, H., \& French, S. (2000). Education on-line: what's in it for women? (Women work and computerization: charting a course to the future). Vancouver, BC: Kluwer Academic Publishers.

- Richardson, J.C., \& Newby, T. (2006). The role of students' cognitive engagement in online learning. The American Journal of Distance Education, 20, 23-37.

- Richardson, J. C., \& Swan, K. (2003). Examining social presence in online courses in relation to students' perceived learning and satisfaction. Journal Asynchronous Learning Network, 7(1), 68-88.

- Riding, R. J. (2002) School learning and cognitive style. David Fulton Publishers. London.

- Riding, R. J., and Agrell, T. (1997) The effect of cognitive style and cognitive skill on school subject performance. Educational Studies, 23, 311-322. 


\section{Number 74, June, 2016}

- Riding, R. J., and Caine, T. (1993) Cognitive style and GCSE performance in mathematic, English language and French. Educational Psychology, 13, 59-67.

- Riding, R. J. \& Cheema, I. (1991). Cognitive styles: an overview and integration. Educational Psychology, 11, 193-215.

- Riding, R. J., and Rayner, S. (1998) Cognitive styles and learning strategies: understanding style differences in learning and behaviour. David Fulton, London.

- Riding, R. J., and Sadler-Smith, E. (1997) Cognitive style and learning strategies: some implications for training design. International Journal of Training and Development, 1, 199-208.

- Rogers, P., \& Lea, M. (2005). Social presence in distributed group environments: The role of social identity. Behavior \& Information Technology, 24(2), 151-158.

- Romiszowski, A., \& Mason, R. (2004). Computer-Mediated Communication. In D. Jonassen (Ed.), Handbook of Research on Educational Communications and Technology (pp. 397-431). Mahwah, NJ: Lawrence Erlbaum Associates, Publishers.

- Rourke, L., \& Anderson, T. (2002). Using peer teams to lead online discussions. Journal of Interactive Media in Education, 1, 1-21.

- Rourke, L., Anderson, Garrrison, and Archer (2001). Assessing social presence in asynchronous text-based computer conferencing. Journal o f Distance Education, 14 (2). Retrieved October 1st from http://cade.athabascau.ca/voll 4.2/rourke et al.html

- Rovai, A. P. (2007). Facilitating online discussions effectively. The Internet and Higher Education, 10(1), 77-88.

- Rovai, A. P., \& Baker, J. D. (2005). Gender differences in online learning: Sense of community, perceived learning, and interpersonal interactions. Quarterly Review of Distance Education, 6(1), 31-44.

- Sadker, M. P., \& Sadker, D. M. (1994). Failing at fairness: how America's schools cheat girls. New York: Scribners Sons.

- Saracho, O. N. (2001) Cognitive style and kindergarten pupils' preferences for teachers. Learning and Instruction, 11, 195-209

- Savicki, V., Kelley, M., \& Ammon, B. (2002). Effects of training on computer-mediated communication in single or mixed gender small task groups. Computers in Human Behavior, 18, 257-269.

- Seo, K. K. (2007). Utilizing peer moderating in online discussions: addressing the controversy between teacher moderation and nonmoderation. American Journal of Distance Education, 21(1), 21-36.

\section{0}




\section{Number 74, June, 2016}

- Shin, S., \& Cho, E. (2003). The culturally situated process of knowledge production in a virtual community: A case of hypertext analysis from a University's Class Web discussion boards. Current Issues in Comparative Education, 6(1)

- Short, J.,Williams, E., \& Christie, B. (1976). The social psychology of telecommunication. London:Wiley.

- Sierpe, E. (2001). Gender and participation in computer-mediated LIS education topical discussions: an examination of JESSE, the Library/Information Science Education Forum. Journal of Education for Library and Information Science, 42(4), 339-347.

- Sierpe, E. (2000). Gender and technological practice in electronic discussion lists: an examination of JESSE, the library/information science education forum. Library and Information Science Research, 22, 273-289.

- Sproull, L., \& Kiesler, S. (1986). Reducing social context cues: electronic mail in organisational communication. Management Science, 32, 1492-1512.

- Stacy, E. \& Rice, M. (2002). Evaluating an online learning environment. Australian Journal of Educational Technologies, 18(3), 323-340.

- Sternberg, R. J. (1997) Thinking styles. NY: Cambridge University Press.

- Summerville, J. (1999) Role of awareness of cognitive style in hypermedia [Electronic version] International Journal of Educational Technology. Available online: http://www.outreach.uiuc.edu/ijet/v1n1/summerville/. Last date accessed: April 23, 2015.

- Swan, K. (2003). Learning effectiveness: What the research tells us. In J. Bourne \& J. C. Moore (Eds.), Elements of Quality Online Education, Practice and Direction (pp. 13-45).Needham, MA: Sloan Center for Online Education.

- Swan, K., \& Shih, L. F. (2005). On the nature and development of social presence in online course discussions. Journal of Asynchronous Learning Networks, 9(3), 115-136.

- Tennant, M. (1988) Psychology and Adult Learning. London: Routledge.

- Tennen, D. (1990). You just don't understand: women and men in conversation. New York: Ballantine. 


\section{Number 74, June, 2016}

- Teo, T., \& Lim, V. (2000). Gender differences in Internet usage and task preferences. Behavior and Information Technology, 19, 283295.

- Thompson, J. (2010). Best Practices in Online Discussions: Insights From 10 Years' Experience Teaching Online Courses. Presented at the 16th Sloan-C International Conference on Online Learning. November 3-5, Orlando Florida.

- Thompson, M. M. (1998). Distance learners in higher education. In C. C. Gibson (Ed.), Distance learners in higher education: Institutional responses for quality outcomes (pp. 9-24). Madison, WI: Atwood Publishing.

- Thompson, P. (2013). The digital natives as learners: Technology use patterns and approaches to learning. Computers \& Education, $65,12-33$.

- Thompson, E.W., \& Savenye, W.C. (2007). Adult learner participation in an online degree program: A program-level study of voluntary computer-mediated communication. Distance Education, 28, 299-312.

- Traphagan, T., Kucsera, J. V., \& Kishi, K. (2010). Impact of class lecture webcasting on attendance and learning. Educational Technology Research and Development, 58(1), 19-37.

- Thurlow, C., Lengel, L., \& Tomic, A. (2004). Computer mediated communication. Thousand Oaks, CA: Sage.

- Walther, J. B. (1992). Interpersonal effect in computer-mediated interaction: a relational perspective. Communication Research, 19, $50-88$.

- Wang, Y., \& Chen, V. (2008). Essential elements in designing online discussions to promote cognitive presence: A practical experience. Journal of Asynchronous Learning Networks, 12(3), $157-157$

- Web, E., Jones, A., Barker,. P. \& Van, S. P. (2004). Using e-learning dialogues in higher education. Innovation in Education and Teaching International, 41(1), 93-103.

- Weaver, D. (2008). Academic and student use of a learning management system: Implications for quality. Australasian Journal of Educational Technology, 24, 30-41. 


\section{Number 74, June, 2016}

- Wood, W. \& Rhodes, N. D. (1992). Sex differences in interaction style in task group. In Ridgeway, C. (Ed), Gender, interaction, and inequality (pp.97-121). New York: Springer-Verlag.

- Wise, K., Hamman, B., \& Thorson, K. (2006). Moderation, response rate, and message interactivity: Features of online communities and their effects on intent to participate. Journal of Computer-Mediated Communication, 12(1).

- Witkin, H. (1950) Individual differences in the ease of perception of embedded figures. Journal of Personality, 19, 1-15.

- Witkin, H. (1964) Origins of cognitive style. In C. Sheerer (Ed.), Cognition: theory, research, and promise. NY: Harper and Row.

- Witkin, H., and Asch, S. E. (1948) Studies in space orientation: IV. Further experiments on perception of the upright with displaced visual fields. Journal of Experimental Psychology, 38, 762-782.

- Witkin, H. A., \& Goodenough, D. (1981). Cognitive styles, essence and origins: Field dependence and field independence. New York: International Universities.

- Witkin, H., and Moore, C. A. (1974) Cognitive style and the teaching of learning process. Paper presented at the annual meeting of the American Educational Research Association (59th, Chicago, Illinois, April 1974, P.33).

- Witkin, H. A., Moore, C. A., Goodenough, D. R., Cox, P. W. (1977). Field-dependent and field-independent cognitive styles and their educational implications. Review of Educational Research, 47(1), 164.

- Witt, P. A., Wheeless, L. R., \& Allen, M. (2004). A meta-analytical review of the relationship between teacher immediacy and student learning. Communication Monographs, 71(2), 184-207.

- Wolfe, J. (2000). Gender, ethnicity, and classroom discourse. Written Communication, 17(4), 491-519.

- Wozniak, H. (2007). Empowering learners to interact effectively in asynchronous discussion activities. In M. Bullen \& D. P. Janes 
(Eds), Making the transition to e-learning: strategies and issues (pp. 208-224). Hershey, NY: Information Science Publishing.

- Yates, S. J. (1997). Gender, identity and CMC. Journal of Computer Assisted Learning, 13, 281-290.

- Yates, S. J. (2001). Gender, language and CMC for education. Learning and Instruction, 11, 21-34.

- Yeh, H.-T., \& Lahman, M. (2007). Pre-service teachers' perceptions of asynchronous online discussion on Blackboard. Qual Rep, 12(4), 680-704.

- Yukselturk, E. (2010). An investigation of factors affecting student participation level in an online discussion forum. The Turkish Online Journal of Educational Technology, 9(2).

- Zhao, N., \& McDougell, D. (2005). Cultural factors affecting Chinese students' perception in asynchronous online discussion. In G. Richards (Ed.), Proceedings of the world conference on elearning in corporate, government, and higher education 2005 (pp. 2723-2729). Chesapeake, VA: AACE.

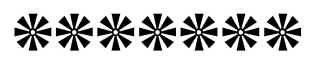

